\title{
Have Peak Fishery Production Levels been Passed in Continental Shelf Areas? Some Perspectives Arising from Historical Trends in Production per Shelf Area
}

\author{
J. F. Caddy, F. Carocci and S. Coppola \\ Fishery Resources Division, Food and Agriculture Organization of the United Nations \\ Rome, Italy
}

\begin{abstract}
Trends in landings from global shelf areas (excluding the Arctic/Antarctic) for 195094 are expressed per shelf surface of FAO Statistical Areas in four categories: "shelfdependent" species (demersal fish plus commercial benthic invertebrates), "shelf-associated" species (small-medium sized pelagics and neritic squids), and "deep-water" and "oceanic" species; largely focusing on the first two categories.

Geographical variation for shelf-dependent resources is explained by dividing FAO Statistical Areas into three categories: Arcto-boreal regions in the northern hemisphere, with five-year mean fishery production peaking at 2.1-2.7 tons per $\mathrm{km}^{2}$; from the Antarctic convergence to south-boreal latitudes, with production peaking at $0.5-2.2$ tons per $\mathrm{km}^{2}$, and tropical/subtropical shelves, peaking at $0.4-0.9$ tons per $\mathrm{km}^{2}$ (except for the Central East Atlantic). For zoogeographically similar areas, overall production levels for shelf-dependent resources have generally reached similar peak values and declined recently in areas with long histories of fishing. For several areas, especially in the tropics, production peaked in the last five-year period considered, 1990-94, but further potential for shelf-dependent species is considered limited. A low limit for shelf-dependent resources in the tropics of $<1$ tons per $\mathrm{km}^{2}$ reflects peak production well inside $200 \mathrm{~m}$, despite local highly productive coastal ecosystems. Mediterranean shelf-dependent production was at tropical/sub-tropical levels in the 1960s but has increased through the 43-year time series to 2.4 tons per $\mathrm{km}^{2}$, similar to north-boreal shelves. As for other inland seas, this increase probably represents, at least in part, nutrient runoff effects on marine production.
\end{abstract}

The upper limit for shelf-associated resources is more variable than for shelf-dependent resources and may be an index of biological productivity. Production of small-medium pelagic fish is considered loosely correlated with shelf-dependent production, and in Arctoboreal regions may be dependent on nutrients from shelf water mixing, while high shelf pelagic production is confined to upwelling regimes. Globally, the recent rate of production increase for oceanic and deep-water species exceeds that for shelf resources, pointing to the recent diversion of effort to offshore areas.

The apparent difference in shelf-dependent production in similar North and South temperate areas is suggested to be due to a greater "land effect", roughly estimated at some 1.00-1.5 tons per $\mathrm{km}^{2}$ for comparable levels of production of small pelagics. This difference is postulated as due to increased nutrient runoff and/or larval retention on northern than the more exposed southern hemisphere shelves, and an analogy is drawn between effects of excessive "natural eutrophication" and that due to anthropogenic causes. Although nutrients may constrain local production, resources closely linked to continental shelves are overfished or potentially so, and recovery will only be achievable by better management. One estimate derived from this study suggests that the potential for recovery by improved management of shelf-dependent resources is of the order of 7 million tons globally (not including a reduction in discarding).

Keywords: catch trends, continental shelves, ecosystems, nutrients, regional/global 


\section{Introduction}

For the great majority of world fisheries, information on stock size or biomass is fragmentary or absent, and statistical data on the state of resources has to be derived by deduction from reported landing data provided to FAO by its member countries. Given the evident problems of uneven reporting and the absence of comparable information on fishing intensity, or even fleet size by region in some cases, conclusions such as those reported here, based on a preliminary analysis of this global database of fisheries landings, are necessarily very tentative but are difficult to substitute for in any discussion of the state of world marine fisheries. In fact, this FAO database (1995a) has recently supported a number of generalizations. From this and a variety of other sources, FAO (1995a and b) suggested that we are currently at or approaching the limits for marine production, at least under current fishing regimes.

The widely paraphrased statement (FAO, 1995c) that "69\% of the world's marine stocks, for which data are available, were either fully to heavily exploited (44\%), over-exploited (16\%), depleted (6\%), or very slowly recovering from overfishing (3\%)", has reinforced the general perception that the days of uncontrolled expansion of world fisheries are over and has contributed to the acceptance of the need to end open access fishery regimes and cure the chronic current problem of vessel overcapacity affecting world fisheries (FAO, MS 1993). It also set the scene in 1993-95 for international progress with the introduction of a Code of Practice for Responsible Fisheries (FAO, 1995d) and new criteria for management of highly migratory species and straddling stocks (UN, MS 1995).

It is necessary, however, to have a conceptual view of the significance of landing trends to be able to make sense of apparent regularities seen when fisheries are viewed at a high level of aggregation, notably by major oceanic region. At this level of aggregation, single species models do not have much immediate application, and it is necessary to propose a simple model of the evolution of fisheries that is compatible with available data. Such an approach was followed in another study of the long-term FAO data series on global fishery landings: Grainger and Garcia (1996) looked at the rate of change of multi-species landings with time in major oceanic areas and concluded that the time series of fisheries landings for all fisheries in combination follow a regular sequence of stages, from "underdeveloped", "developing", "mature" to "senescent" (Caddy, 1984), with increments in total landings declining progressively in a close to linear fashion to a point in time when a net positive increment in multi-species production disappears. This has occurred for most FAO Statistical Areas, in some cases a decade or more ago, and a few exceptions include the Western Indian Ocean and possibly the Mediterranean. The present study adds another set of information to this analysis by expressing fishery production in terms of the shelf area within the 200-m isobath for each major FAO Statistical Area as determined by Geographical Information System (GIS) methods.

\section{Methods and Rationales}

\section{Shelf Areas}

It seems logical to express productivity in terms of the area of shelf available, and the $200-\mathrm{m}$ isobath is one commonly used - if arbitrary - reference point. The choice of any single bathymetric cut-off point is debatable of course, given that deep-water trawling in north- and south-boreal regions is now harvesting resources at the lower fringes of the shelf and slope, as well as on sea mounts and oceanic ridges. In contrast, in the tropics, harvestable levels of demersal fish biomass tend to be associated with depths significantly shallower than $200 \mathrm{~m}$, and in fact much of the fisheries productivity of bottom-dwelling species is associated with depths inside $50 \mathrm{~m}$. From the available data for exclusively Arctic and Antarctic Statistical Areas it would have to be concluded that the overall productivity is very low, which may not accurately reflect the actual situation, largely due to the fragmentary nature of statistical reporting and the difficulties of deciding what proportion of the shelf areas are ice-free for fishery operations. Hence, these areas were excluded from this study.

Further analyses could be carried out using different bathymetric cut-off points that are more appro-

priate to the region in question but, since global fisheries landing data are not stratifiable by depth of 
capture, whatever choice is made seems equally arbitrary. Further bathymetric analysis by statistical area would be needed to see the consequences of using different cut-offs but, given the lack of assignation of catches by depth, this may not provide much extra real information. It would seem better for the moment, therefore, to choose a common standard for comparison and be prepared to discuss exceptions as they arise. For the moment, the species categorization used in this paper attempts to classify species landed as closely as possible by reference to the $200-\mathrm{m}$ isobath in terms of their predominant depth range or habitat, but no information is available to allow "shares" of landings of a given taxonomic class to be assigned to two or more categories of depth or habitat.

Shelf area estimates used in this study come from the IOC/IHO/BODC "GEBCO Digital Atlas"1. The FAO Statistical Area boundaries (Fig. 1) are taken from specifications given in the FAO Yearbook (FAO, 1994). These were overlaid, edited and checked using the software PC Arc/Info v 3.4d (ESRI, 380 New York Street, Redlands, CA, USA 92373, 1992). Table 1 gives the figures obtained for shelf area within the 200-m isobath from this database.

\section{Species Categories as Measures of "Shelf Production"}

Reported fishery landings (FAO, 1994, 1995a) were summed for each FAO Statistical Area using the International Standard Statistical Classification of Aquatic Animals and Plants (ISSCAAP) categories. As

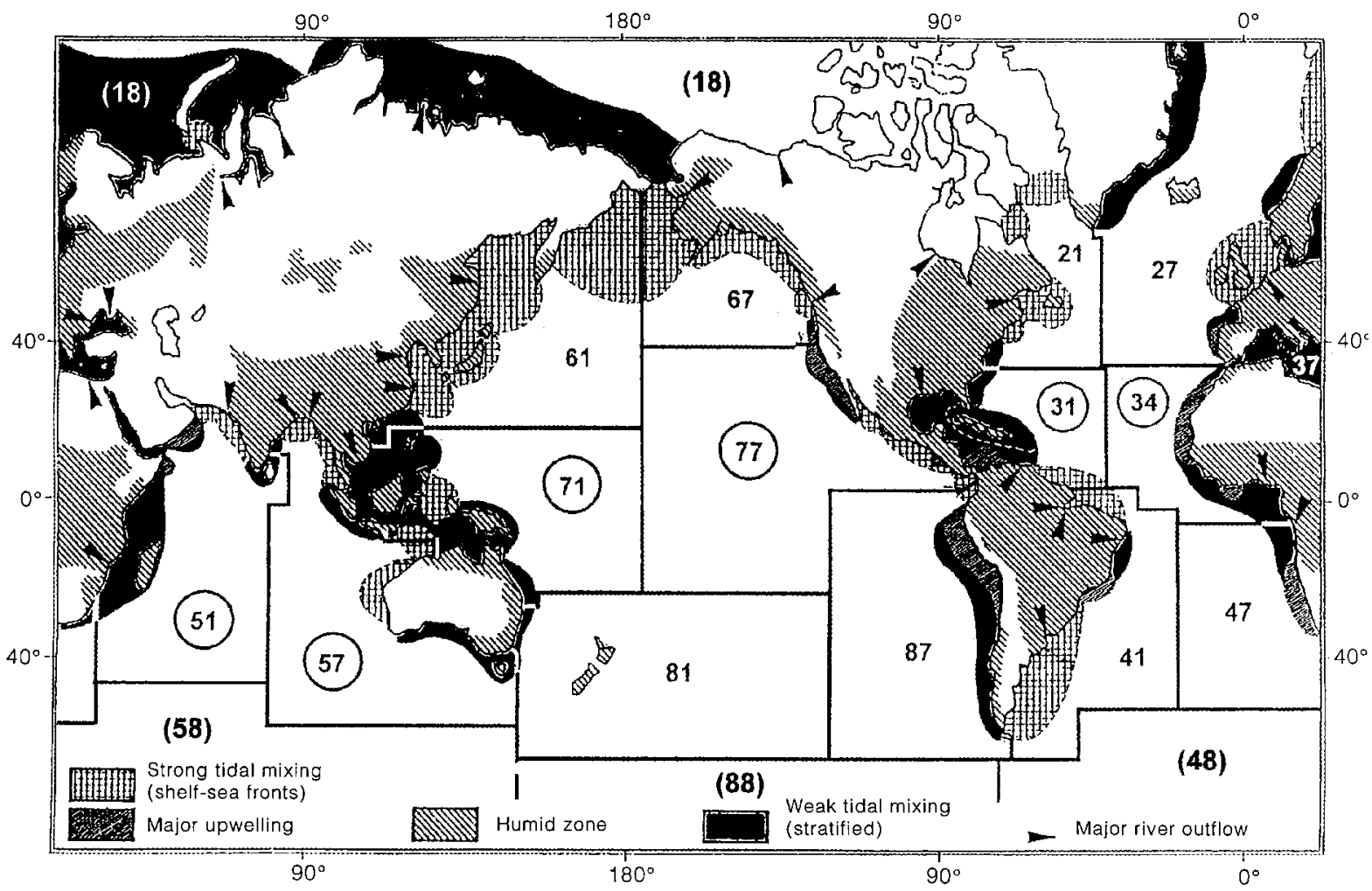

Fig. 1. Showing the boundaries of FAO Statistical Areas discussed in this study. The circled circum-tropical areas separate those exclusively in the northern hemisphere (referred to as north-boreal) form the southboreal areas in the southern hemisphere. Exclusively Arctic and Antarctic Statistical Areas not discussed in this study are shown in brackets. Predominant sources of nutrients are also shown from Caddy and Bakun (1994).

${ }^{1}$ IOC = Intergovernmental Oceanographic Commission; IHO = International Hydrographic Organization; BODC: British Oceanographic Data Centre; GEBCO = General Bathymetic Chart of the Oceans. 
TABLE 1. Approximate shelf areas within the 200-m isobath calculated for FAO Statistical Areas using the GEBCO database (Arctic and Antarctic Oceans are not included in study and are given in brackets) (after Caddy and Bakun, 1994).

\begin{tabular}{cccc}
\hline \hline $\begin{array}{c}\text { FAO Marine } \\
\text { Statistical Areas }\end{array}$ & $\begin{array}{c}\text { Continental Shelf } \\
\text { Area }\left(\mathrm{km}^{2}\right)\end{array}$ & $\begin{array}{c}\text { Total Surface Statistical } \\
\text { Area }\left(\mathrm{km}^{2}\right)\end{array}$ & $\begin{array}{c}\text { \% Shelf Area in } \\
\text { Statistical Area }\end{array}$ \\
\hline$(18)$ & 4482818 & 9221191 & 48.6 \\
71 & 6611254 & 33895792 & 19.5 \\
27 & 2745303 & 14339495 & 19.1 \\
61 & 3632571 & 18732320 & 19.4 \\
41 & 1961493 & 17544243 & 11.2 \\
57 & 2374430 & 29880974 & 7.9 \\
51 & 1896583 & 30182030 & 6.3 \\
31 & 1533538 & 14644554 & 10.5 \\
21 & 1294988 & 6264844 & 17.6 \\
67 & 1336799 & 7593935 & 22.9 \\
37 & 683540 & 2987897 & 1.8 \\
34 & 654364 & 14117658 & 1.7 \\
87 & 569318 & 30798153 & 2.3 \\
77 & 806464 & 48246376 & 1.5 \\
47 & 422667 & 18362308 & 1.7 \\
81 & 409520 & 27658085 & 1.4 \\
$(48)$ & 207613 & 11816903 & 1.4 \\
$(58)$ & 175311 & 12621371 & 8.2 \\
$(88)$ & 137308 & 9527432 & \\
Totals & 293832 & 358435570 & \\
\hline
\end{tabular}

noted, published marine catches from intensive aquaculture ${ }^{2}$ as well as catches of marine plants, corals, anadromous and catadromous fish production and marine mammals were excluded from the estimates (although only marine plants would have had in some areas a noticeable influence on the overall multispecies fisheries production).

Rather than treating each taxonomic category in the database separately, a more modest target was adopted by working, wherever possible, at the ISSCAAP group level of aggregation. However, specific exceptions are made where a species is believed to differ markedly from the rest of its group in its habitat and distribution. The result is that landing records were assigned accordingly:

- Firstly, by ISSCAAP Group (Table 2) to one of the four predominant categories recognized and, secondly (Table 3), exceptions were assigned to a more appropriate category (Fig. 2). The categories used were:

A. Predominantly demersal and/or benthic resources and those restricted to the continental shelf for most of their exploitable life history ("shelf-dependent resources")

B. Those motile, pelagic resources which nonetheless spend much of their exploitable life history in shelf or immediately adjacent waters ("shelf-associated resources").

C. Pelagic species, which are mainly caught offshore (even if a small proportion is incidentally taken or occurs over shelf waters), are included in the ("oceanic resources") category.

2 It is assumed that the majority of production from extensive aquaculture is in coastal waters and benefits from natural productivity of shelf waters. 
D. "Deep-water resources" (see Table 3), which are also occasionally caught in outer shelf waters but predominantly on the continental slope, sea mounts and in deep water.

- The shares of landings calculated for the exceptions listed in Table 3 were then transferred to a more appropriate category. For example, landings for ISSCAAP Group 38 (sharks, rays, chimaeras) were considered primarily shelf-dependent (= Category A), but pelagic sharks were assigned to Category C and chimaeras to Category D.

A species has to be assigned entirely to one of the above four categories, even though some species move vertically in the water column and disperse or migrate on or off the shelf in their life history. The intention of the categorization was primarily to exclude, to the extent possible, oceanic and deep-water resources not associated with shelf ecosystems from the estimates of shelf productivity developed here, and to arrive at one or more realistic measures of the fishery productivity of continental shelf fishery productivity that can be compared between regions. The species categorization and allocation was based

TABLE 2. Predominant categories (A-D) of assignment of ISSCAAP Groups.

\begin{tabular}{cl}
\hline \hline ISSCAAP Number & Resource category \\
\hline
\end{tabular}

A. Shelf dependent resources:

Invertebrates

$\begin{array}{ll}42 & \text { Sea spiders, crabs, etc. }{ }^{1} \\ 43 & \text { Lobsters, spiny-rock lobsters, etc. } \\ 44 & \text { Squat lobsters } \\ 45 & \text { Shrimps, prawns, etc. (excluding estimated aquaculture production) }{ }^{1} \\ 47 & \text { Miscellaneous marine crustaceans } \\ 52 & \text { Abalones, winkles, conchs, etc. } \\ 53 & \text { Oysters }^{2} \\ 54 & \text { Mussels }^{2} \\ 55 & \text { Scallops, pectens, etc. }^{2} \\ 56 & \text { Clams, cockles, arkshells, etc. } \\ 57 & \text { Squids, cuttlefishes, octopuses, etc. }{ }^{2} \\ 58 & \text { Miscellaneous marine molluscs } \\ \text { mersal Marine fishes } & \\ 31 & \\ 32 & \text { Flounders, halibuts, soles, etc. }{ }^{1} \\ 33 & \text { Cods, hakes, haddocks, etc. }{ }^{1} \\ 38 & \text { Redfishes, basses, congers, etc. }^{1} \\ 39^{1} & \text { Sharks, rays, chimaeras, etc. }^{1}\end{array}$

B. Shelf-associated resources:

$\begin{array}{ll}34 & \text { Jacks, mullets, sauries, etc. } \\ 35 & \text { Herrings, sardines, anchovies, etc. } \\ 37 & \text { Mackerels, snoeks, cuttlassfishes, etc. } \\ 39^{1} & \text { Miscellaneous marine fishes }\end{array}$

C. Oceanic resources: 


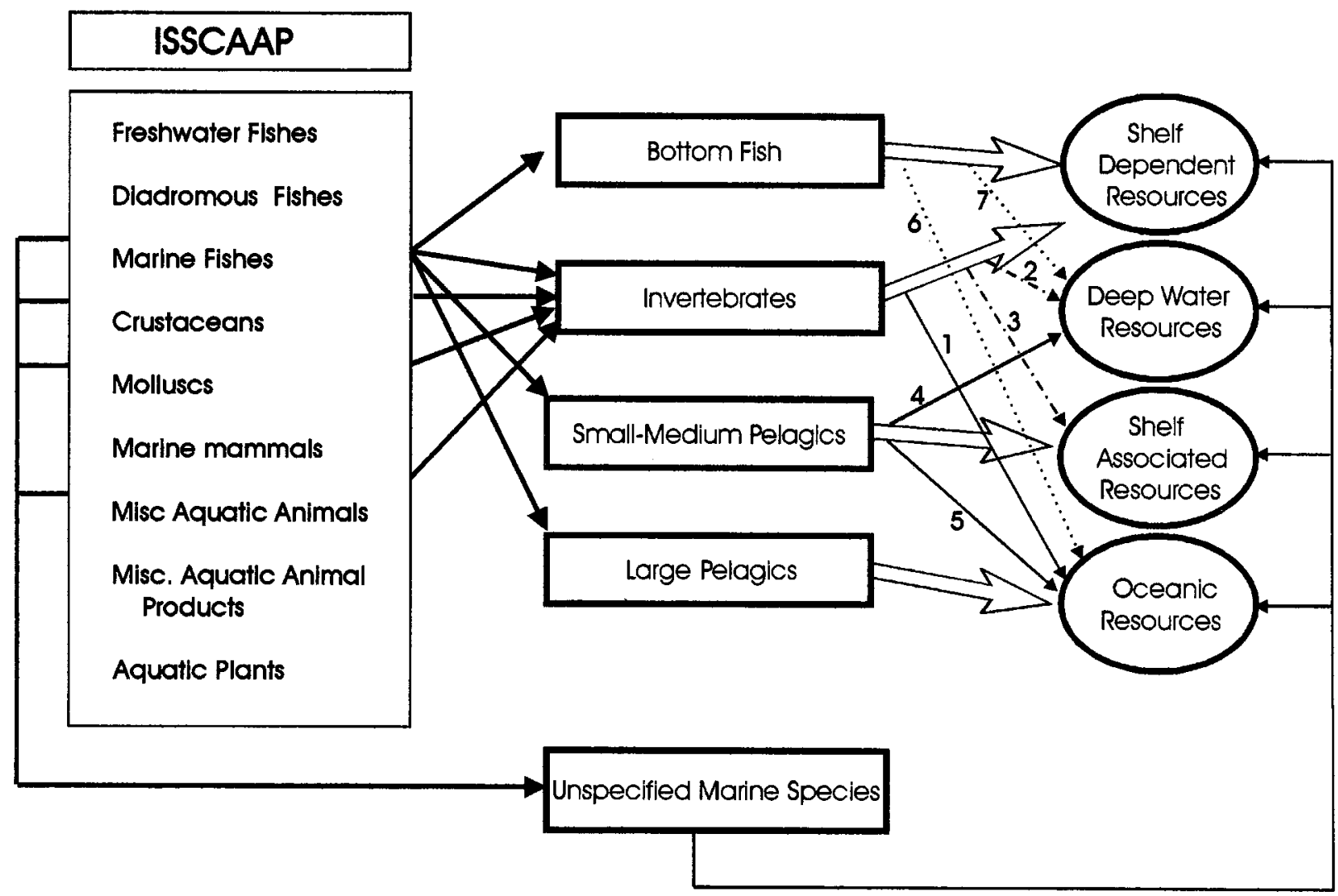

Fig. 2. Illustration of the strategy for first assigning ISSCAAP groups to their predominant "species/habitat type" (e.g. bottom fish, invertebrates). Exceptions were then assigned (numbered lines on the right of the diagram) to the four categorizations followed in this study shown on the right. [Some examples of numbered exceptions given in Table 3 are: 1, oceanic squids; 2, deep water crustaceans; 3, jellyfishes; 4, scabbard fishes, etc.; 5, dolphin fishes etc.; 6, pelagic sharks, and 7, Blue whiting, orange roughy, etc. Landings unspecified by group were assigned in proportion to identified tonnages of their constituent groups].

on judgements from distributional information, especially in the FAO Species Identification Sheets, of the degree to which the productivity of a group of organisms is associated with upper shelf waters and their ecosystems.

The errors resulting from assigning a species to an incorrect category are probably considerably exceeded by those due to other characteristics of the FAO Catches and Landings Data set, which was not primarily designed for ecological categorizations, and such errors are difficult to correct for in the absence of detailed analysis of reported statistics at the national level. The overriding problem of incomplete national reporting by species category is exemplified by the 1992 reported landings of "common dentex" from the Eastern Central Atlantic (FAO Statistical Area 34) which fall into the following statistical subsets:

1. Species (e.g. common Dentex, Dentex dentex)

2. Genus (e.g. Dentex sp. or nei (= not elsewhere included))

3. ISSCAAP Group (porgies, seabreams nei)

4. Marine fishes nei

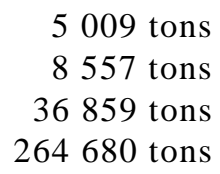

Clearly, classes 2-4 include a proportion of unidentified Dentex dentex. The most obvious, and in fact the only rule that seems feasible, is to assign catches at a higher level of aggregation to a taxonomic category in proportion to the species weights identified in the same fishing area. This, of course poses 
TABLE 3. Some exceptions for Category A ISSCAAP groups (predominantly shelf-dependent resources), which are assigned to categories D, B and C (deep-water, shelf-associated and oceanic resources respectively).

\begin{tabular}{|c|c|c|}
\hline B. Shelf-associated resources & C. Oceanic resources & D. Deep-water resources \\
\hline \multicolumn{3}{|l|}{ Invertebrates: } \\
\hline 57 Martialia hyadesi & 57 Nototodarus sloani & 42 Geryon sp. \\
\hline 57 Illex sp. & 57 Todarodes pacificus & 42 Chionoecetes opilio \\
\hline 77 Rhopilema sp. & 57 Ommastrephidae & $\begin{array}{l}45 \text { Pleoticus sp. } \\
45 \text { Plesiopeneus edwardsianus }\end{array}$ \\
\hline \multicolumn{3}{|r|}{ 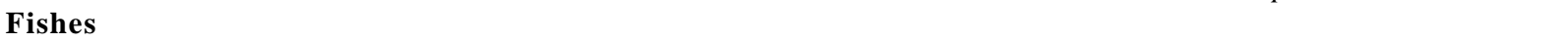 } \\
\hline 33 Caesio sp. & 34 Brama brama & 32 Macrourus sp. \\
\hline 33 Arripes sp. & 34 Coryphaena hippurus & 32 Macruronus sp. \\
\hline 36 Acanthocybium solandri & 34 Cypselurus agoo & 33 Maurolicus sp. \\
\hline 36 Auxis sp. & 34 Lampanyctodes hectoris & 33 Micromesistius sp. \\
\hline 36 Euthynnus sp. & 36 Tetrapturus sp. & 33 Argentina sp. \\
\hline 36 Orcynopsis unicolor & 36 Thunnus alalunga & 33 Glossanodon semifasciatus \\
\hline 36 Sarda sp. & 36 Thunnus albacares & 33 Hoplostethus atlanticus \\
\hline 36 Scomberomorus sp. & 36 Thunnus maccoyii $+T$. thynnus & 33 Hyperoglyphe antarctica \\
\hline 36 Scombroidei nei & 36 Thunnus obesus & 33 Macroramphosus scolopax \\
\hline 36 Thunnus atlanticus & 36 Xiphias gladius & 33 Macrodon ancylodon \\
\hline 36 Thunnus tonggol & 38 Carcharinidae & 33 Emmelichthyidae \\
\hline \multirow[t]{10}{*}{38 Galeorhinus sp. } & 38 Cetorhinus maximus & 33 Dissostichus eleginoides \\
\hline & 38 Isurus sp. & 33 Oreosomatidae \\
\hline & 38 Lamna nasus & 33 Anoplopoma fimbria \\
\hline & 38 Psenes indica & 34 Myctophidae \\
\hline & 38 Psenopsis anomala & 34 Trichiuridae nei \\
\hline & & 35 Alepocephalus bairdii \\
\hline & & 37 Rexea solandri \\
\hline & & 37 Lepidopus caudatus \\
\hline & & 38 Callorhinchus sp. \\
\hline & & 38 Somniosus microcephalus \\
\hline
\end{tabular}

unsolved questions, since almost certainly there will be commercial organisms in each larger aggregation that are not identified to the species level and presumably also an unknown proportion within each species category which are misidentified. Thus, the assignment of a given landing to one or other category has to take account of the characteristics of national reporting of landings to the FAO database, notably that, although landings are assigned by area of capture, a substantial proportion of landings in the FAO database are not reported on at the species level, and hence cannot be directly broken down by species.

"Shelf-dependent resources", although not entirely caught within shelf waters, are largely so. "Shelfassociated resources", consisting of small and medium-sized pelagic fish stocks, are less confined to shelf waters, although much of this pelagic production could also be referred to the continental shelf surface, being significantly dependent on food webs initiated within shelf and closely adjacent waters. These two measures, independently or added together, are probably the best overall indices of shelf production that can be derived from this database, given its characteristics (Table 3). "Shelf-associated" production is also used here as a proxy variable for biological productivity of shelf waters for reasons mentioned later.

The provisos for the main resource categories stem first from the nature of the database, which does not always classify all landings to the species or even family, and this feature of the database probably makes errors in species assignment by one of the four zoogeographical categories of secondary relevance. "Miscellaneous marine fish" (FAO, 1994) were divided between demersal and small pelagic categories in proportion to the amounts identified in the two categories, the assumption being made, that rarely are large pelagic fish a major component of this miscellaneous category. Miscellaneous molluscs and crustaceans result mainly from trawl catches and were all allocated to shelf-dependent resources. Although the 
habitat of cephalopods is very varied, cephalopods were divided in the ratio of identifiable tonnage landed, between shelf-dependent resources (especially Octopoda, Sepioidea, Loliginidae and other neritic squids). Oceanic resources, notably Ommastrephidae nei, which form the main component of landings in offshore areas, have been placed in oceanic resources, but Illex sp. and Martialia sp., which seem to be mainly caught on or along the edge of the shelf, have (debatably) been assigned to the shelf-associated category.

Landings of deep-water demersals are currently only of some importance in FAO Areas 27, 57 and 81, and, although classification by bathymetry is very tentative, a wide variety of organisms with a predominantly deep-water habit include deep water crabs, myctophids, etc, while deep-water fishes of a variety of groups (Table 3), have been placed in Category D. Judging from the trends in Fig. 3, landings in this category, although still minor in many areas, have increased in relation to shelf-dependent species in recent years, and peak five-year averages are generally at the end of the time series (Table 4). Oceanic species were taken to include tunas and tuna-like fish (excluding small coastal tunas and other scombrids), the Ommastrephidae, and a number of small oceanic species mentioned in Table 3.

In conclusion, the scheme proposed here has an inevitable degree of arbitrariness, both with respect to the species categorization chosen and the judgements made with respect to their predominant isobath, but it is hard to see how a much more precise zoogeographical division of resources could be achieved at present given the deficiencies of the data set for this purpose.

\section{Other Sources of Bias}

A further problem, which quantitatively overrides the potential biases due to misclassification mentioned earlier, relates to discards. Alverson et al. (1994) estimated that 19.9-39.5 million tons (with a median value of some 27 million tons) of fisheries production each year are discarded globally in the course of fishing. This global estimate is very tentative and cannot be broken down by statistical area in a consistent way nor can trends be reliably expressed over time without further considerable analysis, nationally and regionally. If global discards were to be added to the global production figures reported here, it would certainly increase them by some $30 \%$, with, of course, very wide ranges by fishery and statistical area that are not possible to quantify at this time. This might be done in future analyses, if the data becomes available, but another reason for not including this component in fishery production estimates

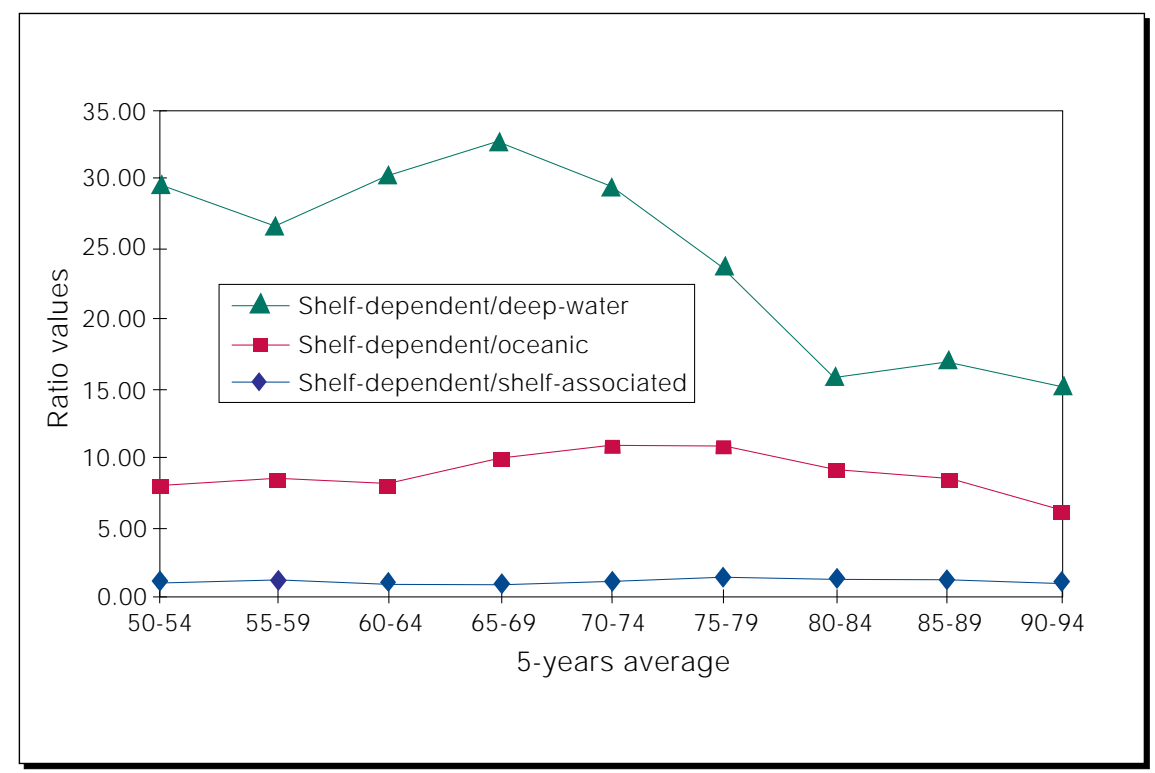

Fig. 3. Trends in ratios between five-year mean values for fishery production of shelf-dependent species and the other 3 categories considered in this study. 
relates to the possible trophic contribution of discards to the harvestable component of food chains and hence of "double counting", if discards were included.

One other potential bias that is difficult to allow for is that, although some countries make estimates of subsistence and small-scale catches before reporting to FAO, these components are not always captured by the FAO database in a consistent way. Other countries communicate estimates to FAO in which the contribution of intertidal, nearshore artisanal and estuarine/anadromous catches may not always be well represented, although, where other information is available, attempts are made to correct these biases before registering the data in the FAO Yearbook. In summary, the data series has deficiencies that make it less than ideal for ecological analysis, but at present there are no alternative data sets at a global level of integration.

\section{Results}

\section{Peak Periods of Fishery Production}

This paper focuses on a description of changes in fishery production for shelf-associated and shelfdependent resources in the FAO Statistical Areas using the data given and treated as described above. Figure 4 shows trajectories for mean shelf production by resource category for all areas included in this study. They show that for most areas there has been a rise in production during the last decades, with a slowing of growth - or a decline - over the last few years. The time lags in this sequence largely reflect, we believe, the spread of industrial fisheries from "core" areas, especially in the North Pacific and Atlantic to other world areas in the seventies and eighties. For roughly half of the areas considered, including those in the northern hemisphere, there has then been a more recent drop in reported fishery production (Table 4).

\section{Shelf-dependent Fishery Production}

In some areas in the southern hemisphere and the tropics, the peak production figure for the shelfdependent category occurred in the last five-year period (1990-94), and conceivably landings might be continuing to rise in these areas (Table 4). However, given the slowing rate of relative annual increase preceding most of these "terminal" estimates (Grainger and Garcia, 1996), the further potential rise for shelf-dependent species is likely to be limited. To what extent these "terminal" peak estimates have potential for further growth, or are comparable with peak values followed by declines, is discussed later, but a first assumption is that the peak five-year averages for fishery production in the time series offer some measure of the multi-species maximum sustainable yield (MSY) for an area. Experience and theory would suggest that single species MSY conditions are staggered in occurrence with time, probably occurring earlier in a given area for longer-lived, lower-fecundity species, and probably for these mostly prior to the peak year of total catch. In other words, an apparent stability of overall yield probably conceals processes of changing dominance of catch composition in time, with short-lived species apparently showing increased relative abundance in the overall catch.

The comment can also be made that most fisheries areas have been effectively open-access in the past and are still weakly managed, especially where shared and straddling stocks are concerned (FAO, 1995b and c; 1997). Therefore, the scheduling of exploitation by species probably has reflected availability to capture and markets rather than any optimal multi-species harvest strategy. This could mean that an overall peak in production (by quantity or value) might have been achieved and sustained by a more carefully planned multi-species fisheries than was actually the case. One of the objectives of future fisheries management would probably be to try to restore a favourable ecological balance such as was presumably the case in the first decade or so of exploitation.

\section{Shelf-associated Resources}

Peak five-year periods were similarly calculated for the shelf-associated species dominated by smallmedium-sized pelagic fish. These peaks in landings do not necessarily coincide in timing with those for 


\begin{tabular}{|c|c|c|c|c|c|c|c|c|c|}
\hline \multicolumn{10}{|c|}{ 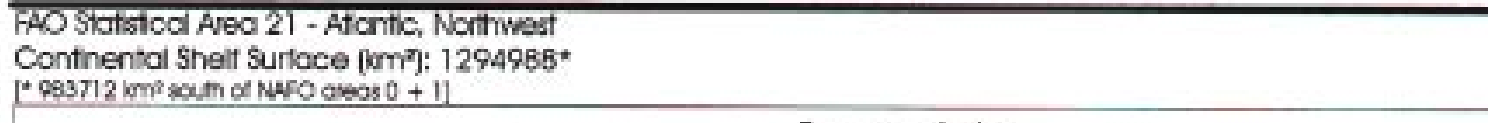 } \\
\hline \multicolumn{10}{|c|}{ 5-year periods } \\
\hline Calegories & 50.54 & 55.59 & $60-64$ & $65-69$ & $70-74$ & 76.79 & $80-84$ & 85-89 & $90-94$ \\
\hline Shelf cosociated & 0.449 & 0.535 & 0.520 & 0.067 & 1.086 & 0.875 & 0.510 & 0.565 & 0.582 \\
\hline Shelf dependient & 1.459 & 1.806 & 2.223 & 2.659 & 2.449 & 1.872 & 1.867 & 2.129 & 1.844 \\
\hline Osecric & 0.002 & 0.003 & 0.013 & 0.009 & 0.009 & 0.010 & 0.011 & 0.010 & 0.010 \\
\hline Deep water & 0.000 & 0.000 & 0.005 & 0.015 & 0.022 & 0.018 & 0.032 & 0.028 & 0.033 \\
\hline Total & 1.910 & 2.343 & 2.760 & 3.350 & 3.566 & 2.775 & 2.421 & 2.731 & 2.469 \\
\hline
\end{tabular}
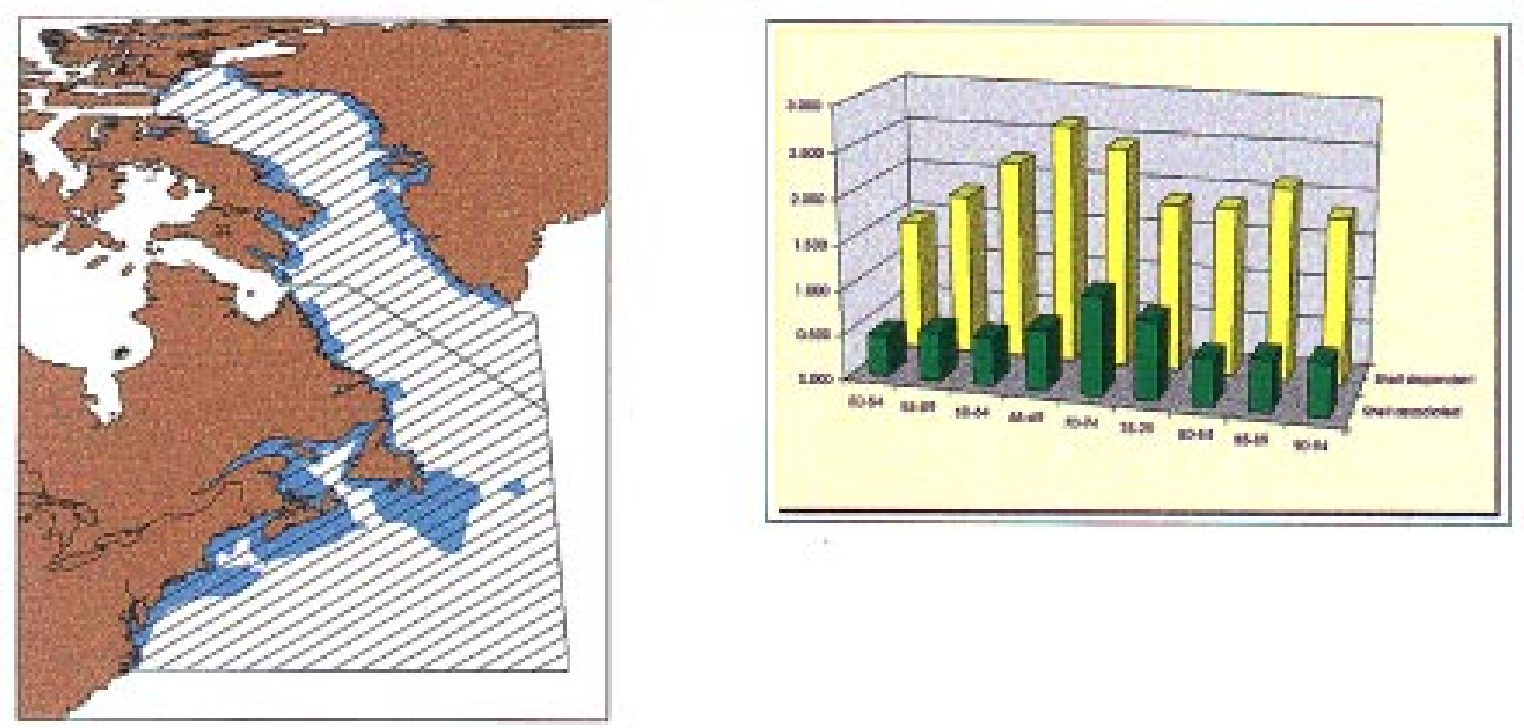

FDO Slatelcal Aved 27 - Atantic, Northecs

Conthental Shelf Surfoce $\left(\mathrm{km}^{2}\right): 2745303$

\begin{tabular}{|c|c|c|c|c|c|c|c|c|c|}
\hline \multirow[b]{2}{*}{ Calegories } & \multicolumn{8}{|c|}{ 5-year periods } & \multirow[b]{2}{*}{$90-94$} \\
\hline & $50-54$ & $55-59$ & $60-64$ & $65-69$ & $70-74$ & $75-79$ & $80-84$ & $85-89$ & \\
\hline Shel associaled & 1.039 & 1.176 & 1.235 & 1.744 & 1.616 & 2.072 & 1.712 & 1.413 & 1.615 \\
\hline Sher dependert & 1.348 & 1.675 & 1.779 & 2063 & 2.578 & 2.704 & 2.605 & 2.603 & 2.376 \\
\hline Oceank & 0.026 & 0.000 & 0.031 & 0.031 & 0.029 & 0.027 & 0.030 & 0.025 & 0.020 \\
\hline Deep woter & 0.005 & 0.006 & 0.007 & 0.010 & 0.017 & 0.155 & 0.276 & 0.261 & 0.193 \\
\hline Total & 2.419 & 2.886 & 3.062 & 3.848 & 4.241 & 4.957 & 4.623 & 4.303 & 4.205 \\
\hline
\end{tabular}
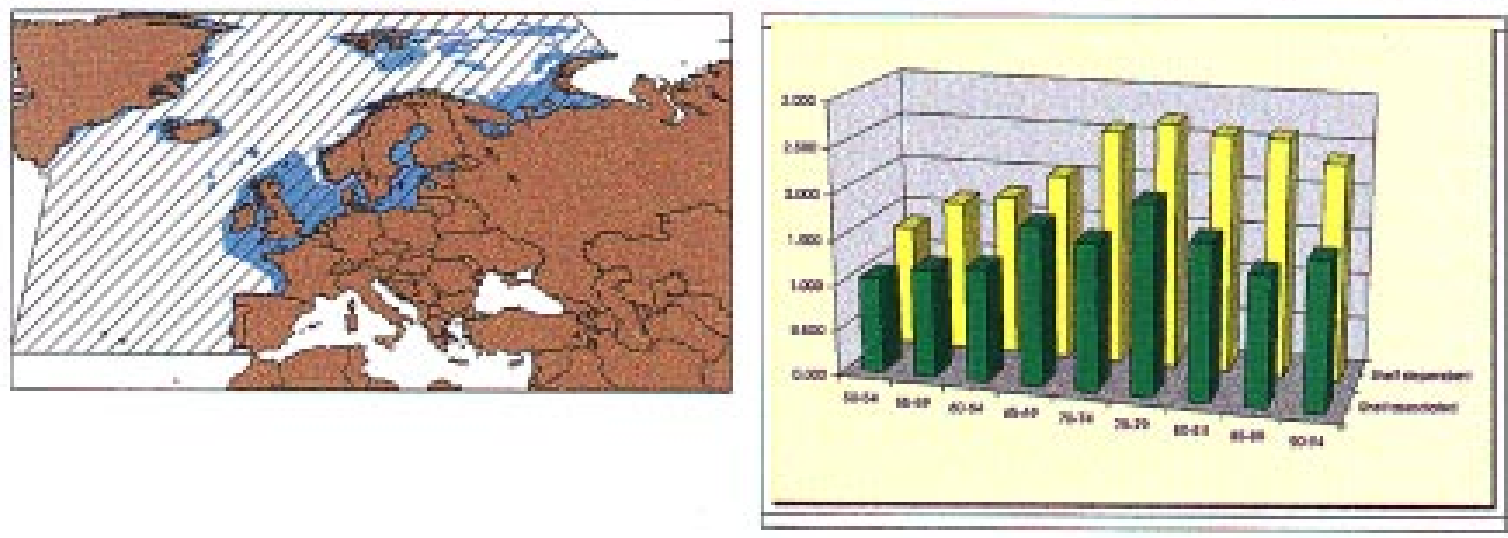

Fig. 4. Summarized five-year averages by category and graphed trajectories of mean landings by fiveyear periods, for Shelf-dependent, Shelf-associated, Oceanic, Deep-water and Total landings from the 15 FAO Statistical Areas considered in this study, for which trends are shown for the five-year averages of the first two. Maps show shelf areas shaded blue. 


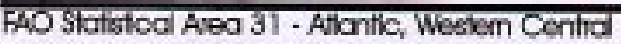
Conthental Sheit Surlace (kn'? 1533538

\begin{tabular}{|c|c|c|c|c|c|c|c|c|c|}
\hline Categorles & $50-54$ & 56.59 & $60-64$ & $\begin{array}{l}5 . y p a r \\
65-69\end{array}$ & $\begin{array}{l}\text { Periods } \\
70-74\end{array}$ & $75-79$ & $80-84$ & $85-89$ & $90-94$ \\
\hline Shet ossociated & 0.211 & 0.275 & 0.398 & 0.390 & 0.477 & 0.531 & 0.652 & 0.609 & 0.492 \\
\hline Shel dependent & 0.313 & 0.359 & 0.420 & 0.565 & 0.688 & 0.730 & 0.792 & 0.713 & 0.706 \\
\hline Oceanic & 0.011 & 0.015 & 0.026 & 0.037 & 0.040 & $0.045^{\circ}$ & 0.065 & 0.066 & 0.073 \\
\hline Deep water & 0.000 & 0.000 & 0.000 & 0.000 & 0.001 & 0.001 & 0.001 & 0.001 & 0.003 \\
\hline Tota & 0.536 & 0.650 & 0.844 & 0.992 & 1.207 & 1.307 & 1.511 & 1.390 & 1.273 \\
\hline
\end{tabular}
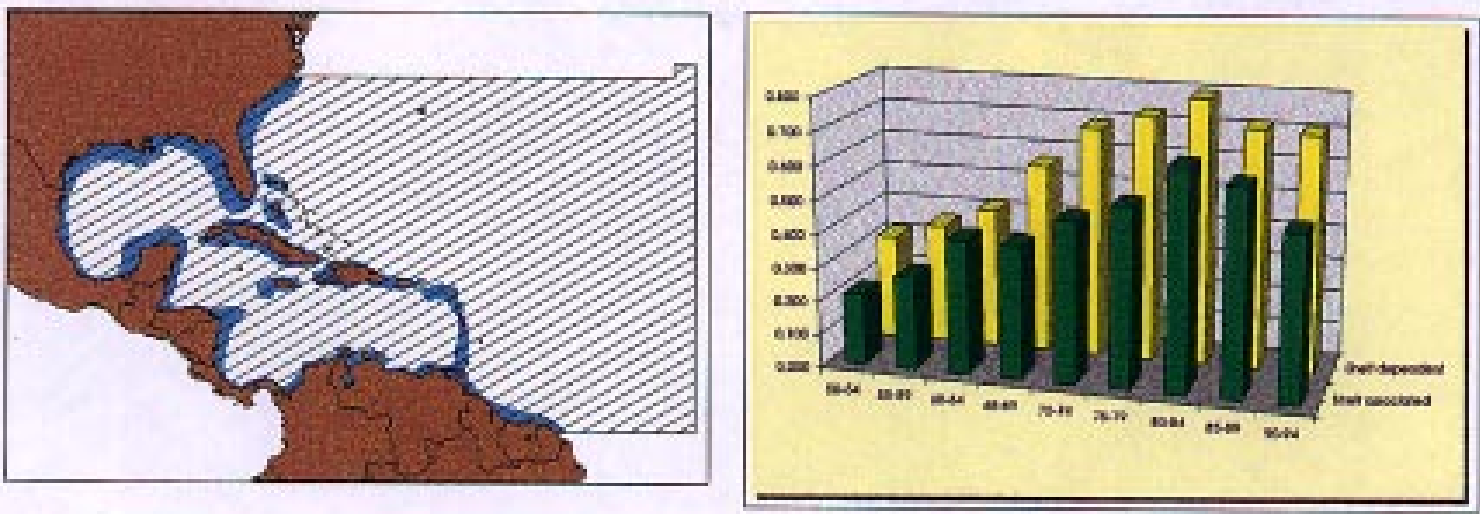

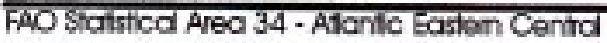

Continental Shelt Surtace $\left(\mathrm{cm}^{2}\right), 654965$

\begin{tabular}{|lcccccccccc|}
\hline Categoties & $50-54$ & $55-59$ & $60-64$ & $65-69$ & $70-74$ & $75-79$ & $80-84$ & $85-89$ & $90-94$ \\
Shelf associated & 0.262 & 0.347 & 0.587 & 1.018 & 2.586 & 2.854 & 2.533 & 3.173 & $\mathbf{3 . 2 5 8}$ \\
Shert dependent & 0.189 & 0.283 & 0.599 & 1.133 & 1.836 & 1.910 & 2.067 & $\mathbf{2 . 2 1 6}$ & 2.012 \\
Oceanic & 0.010 & 0.022 & 0.059 & 0.159 & 0.311 & 0.392 & 0.470 & 0.420 & 0.501 \\
Deep woiter & 0.000 & 0.000 & 0.005 & 0.014 & 0.055 & 0.052 & 0.102 & 0.125 & 0.107 \\
Total & 0.460 & 0.652 & 1.249 & 2.324 & 4.787 & 5.208 & 5.171 & 5.934 & 5.879 \\
\hline
\end{tabular}
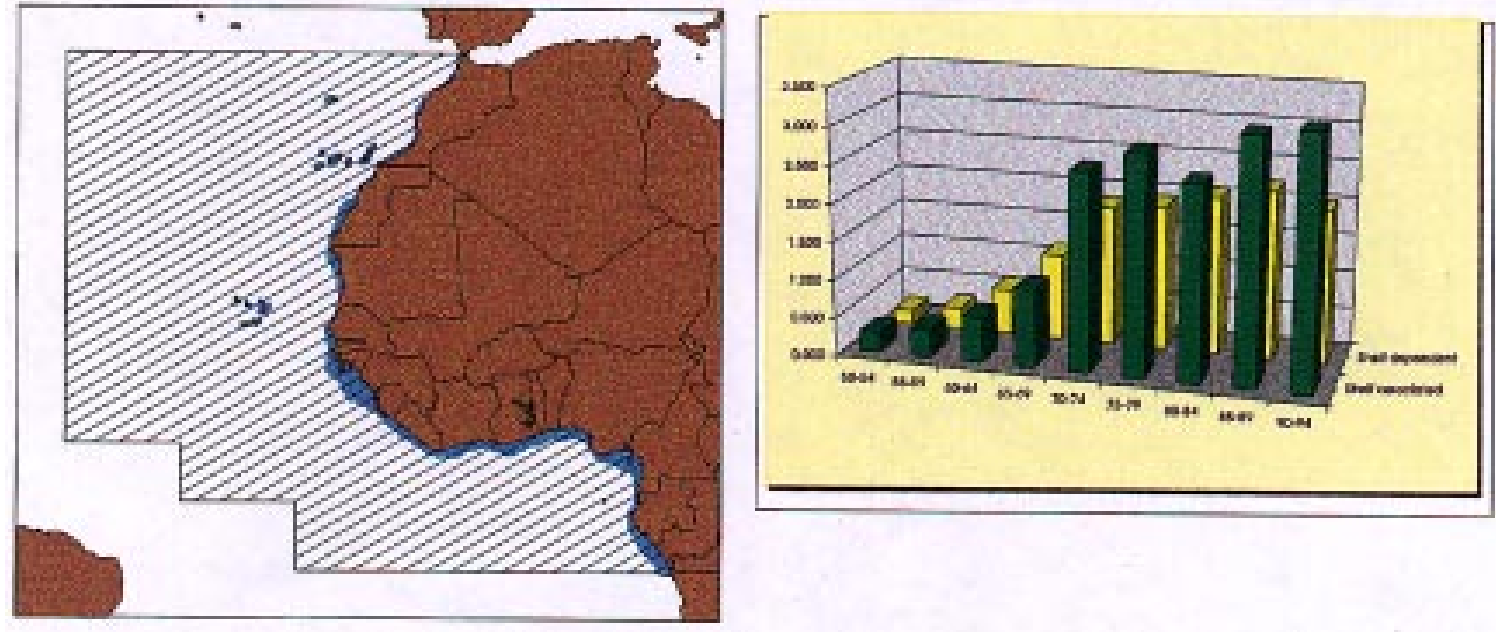

Fig. 4. (Continued). Summarized five-year averages by category and graphed trajectories of mean landings by five-year periods, for Shelf-dependent, Shelf-associated, Oceanic, Deep-water and Total landings from the 15 FAO Statistical Areas considered in this study, for which trends are shown for the five-year averages of the first two. Maps show shelf areas shaded blue. 


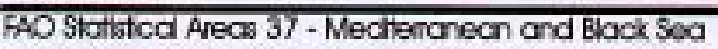
Conthental Shelt Surtoce ( $\mathrm{mm}^{2}$ ), 683540

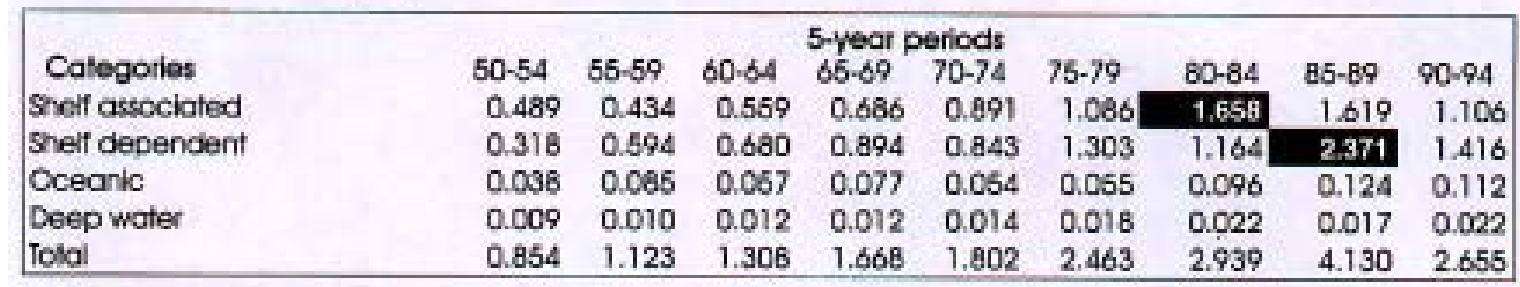
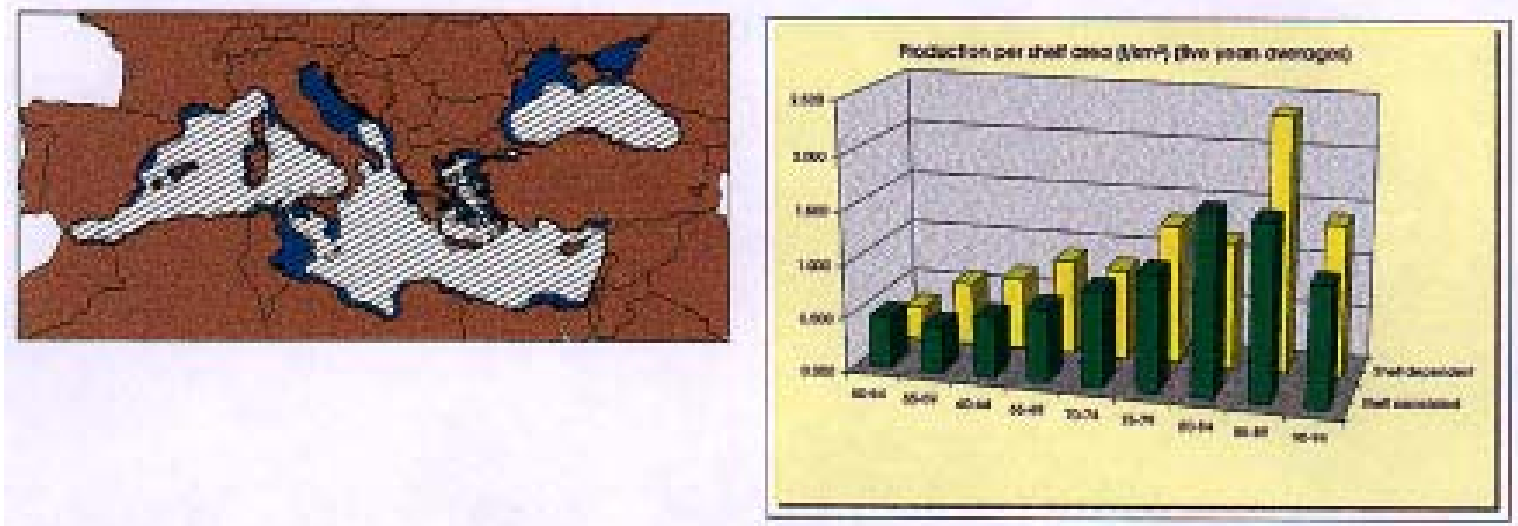

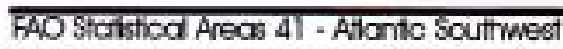 Contnental Sheit Surtace (km²): 1961493}

\begin{tabular}{|lcccccccccc|}
\hline & & \multicolumn{7}{c|}{5 -year periods } \\
Calegorles & $50-54$ & $55-59$ & $60-64$ & $86-\$ 9$ & $70-74$ & $75-79$ & $80-84$ & $85-89$ & $90-94$ \\
Shelf associated & 0.033 & 0.046 & 0.050 & 0.092 & 0.151 & 0.150 & 0.153 & 0.306 & 0.310 \\
Shelf copondent & 0.093 & 0.143 & 0.205 & 0.419 & 0.384 & 0.540 & 0.572 & 0.775 & 0.698 \\
Ocearic & 0.002 & 0.003 & 0.008 & 0.012 & 0.013 & 0.011 & 0.019 & 0.029 & 0.032 \\
Deep wotat & 0.000 & 0.000 & 0.001 & 0.001 & 0.002 & 0.010 & 0.077 & 0.104 & 0.095 \\
Total & 0.128 & 0.193 & 0.274 & 0.524 & 0.550 & 0.711 & 0.821 & 1.214 & 1.134 \\
\hline
\end{tabular}
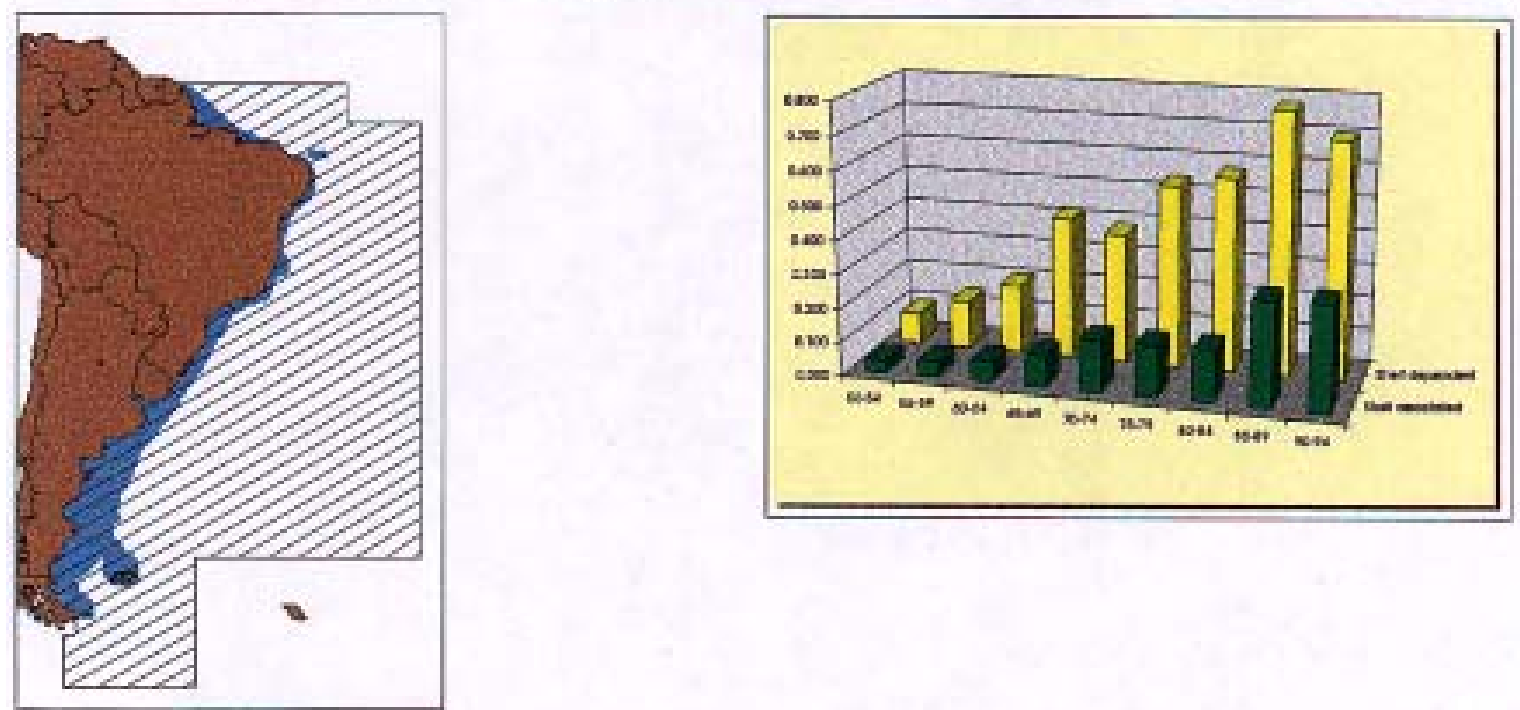

Fig. 4. (Continued). Summarized five-year averages by category and graphed trajectories of mean landings by five-year periods, for Shelf-dependent, Shelf-associated, Oceanic, Deep-water and Total landings from the 15 FAO Statistical Areas considered in this study, for which trends are shown for the five-year averages of the first two. Maps show shelf areas shaded blue. 
FAO STotsical Areas 47 - Afontc Southecsit

Conthental Shelt Surfoce (om²): 422067

\begin{tabular}{|lcccccccccc|}
\hline Calegoties & $50-54$ & $55-59$ & $60-64$ & $65-69$ & $70-74$ & $75-79$ & $80-84$ & $85-89$ & $90-94$ \\
Shelf cssociated & 1.162 & 1.723 & 2.761 & $\mathbf{4 . 4 3 2}$ & 3.773 & 4.368 & 3.711 & 3.684 & 2.360 \\
Shelf dependent & 0.328 & 0.366 & 0.489 & 1.710 & $\mathbf{2 . 5 0 7}$ & 2.079 & 1.530 & 1.717 & 0.828 \\
Oceanic & 0.025 & 0.027 & 0.035 & 0.086 & 0.130 & 0.104 & 0.119 & 0.132 & 0.121 \\
Deep water & 0.001 & 0.004 & 0.009 & 0.017 & 0.020 & 0.059 & 0.043 & 0.049 & 0.045 \\
Total & 1.517 & 2.118 & 3.292 & 6.245 & 6.429 & 6.610 & 5.404 & 5.581 & 3.354 \\
\hline
\end{tabular}

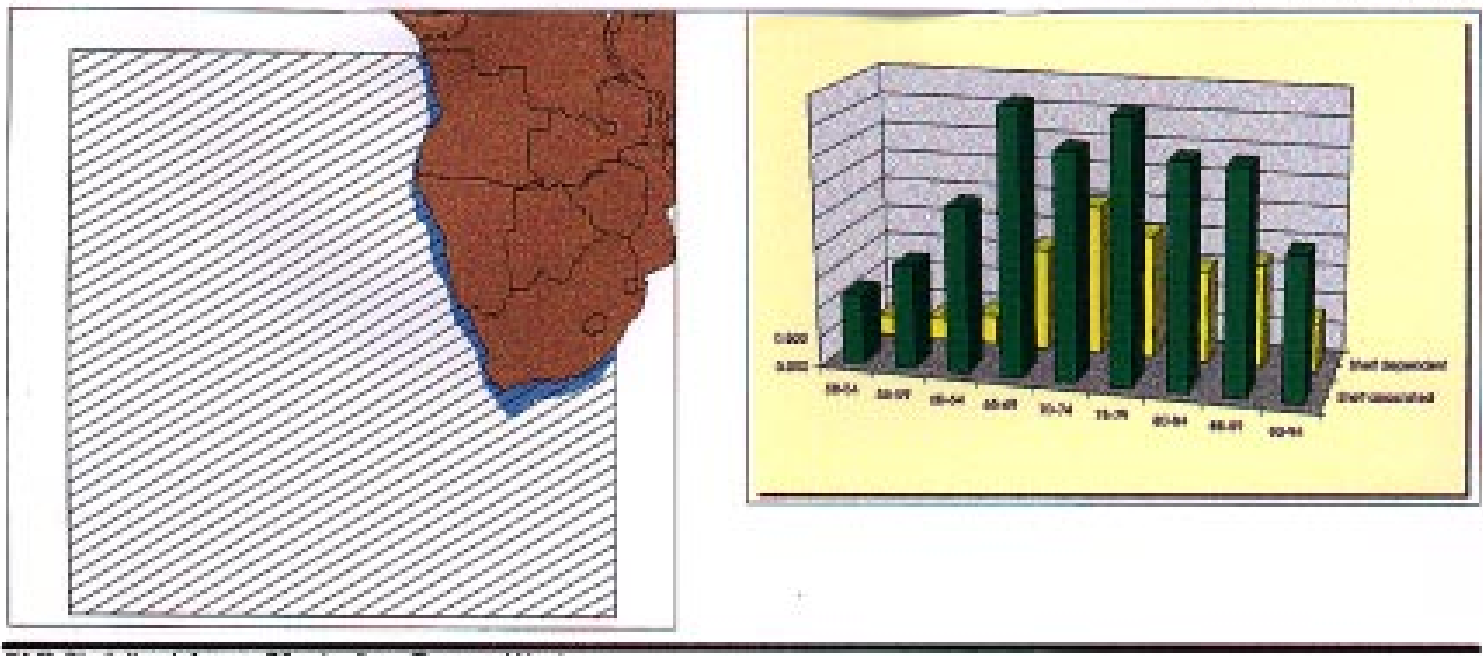

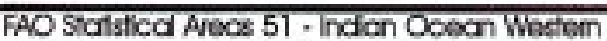

Confinental Shelf Surfoce (om): 1896584

\begin{tabular}{|c|c|c|c|c|c|c|c|c|c|}
\hline \multirow[b]{2}{*}{ Categories } & \multicolumn{8}{|c|}{ 5-year periods } & \multirow[b]{2}{*}{$90-94$} \\
\hline & $50-54$ & $55-59$ & $60-64$ & $65-69$ & $70-74$ & $75-79$ & $80-84$ & $85-89$ & \\
\hline Sheif associcted & 0.114 & 0.161 & 0.214 & 0.273 & 0.328 & 0.338 & 0.368 & 0.383 & 0.475 \\
\hline Sheif dependent & 0.184 & 0.254 & 0.278 & 0.362 & 0.449 & 0.622 & 0.636 & 0.704 & 0.961 \\
\hline Oceanic & 0.019 & 0.028 & 0.040 & 0.107 & 0.109 & 0.116 & 0.140 & 0.294 & 0.402 \\
\hline Deep water & 0.015 & 0.010 & 0.006 & 0.010 & 0.011 & 0.019 & 0.020 & 0.028 & 0.022 \\
\hline Total & 0.332 & 0.452 & 0.598 & 0.752 & 0.697 & 1.096 & 1.164 & 1.409 & 1.859 \\
\hline
\end{tabular}
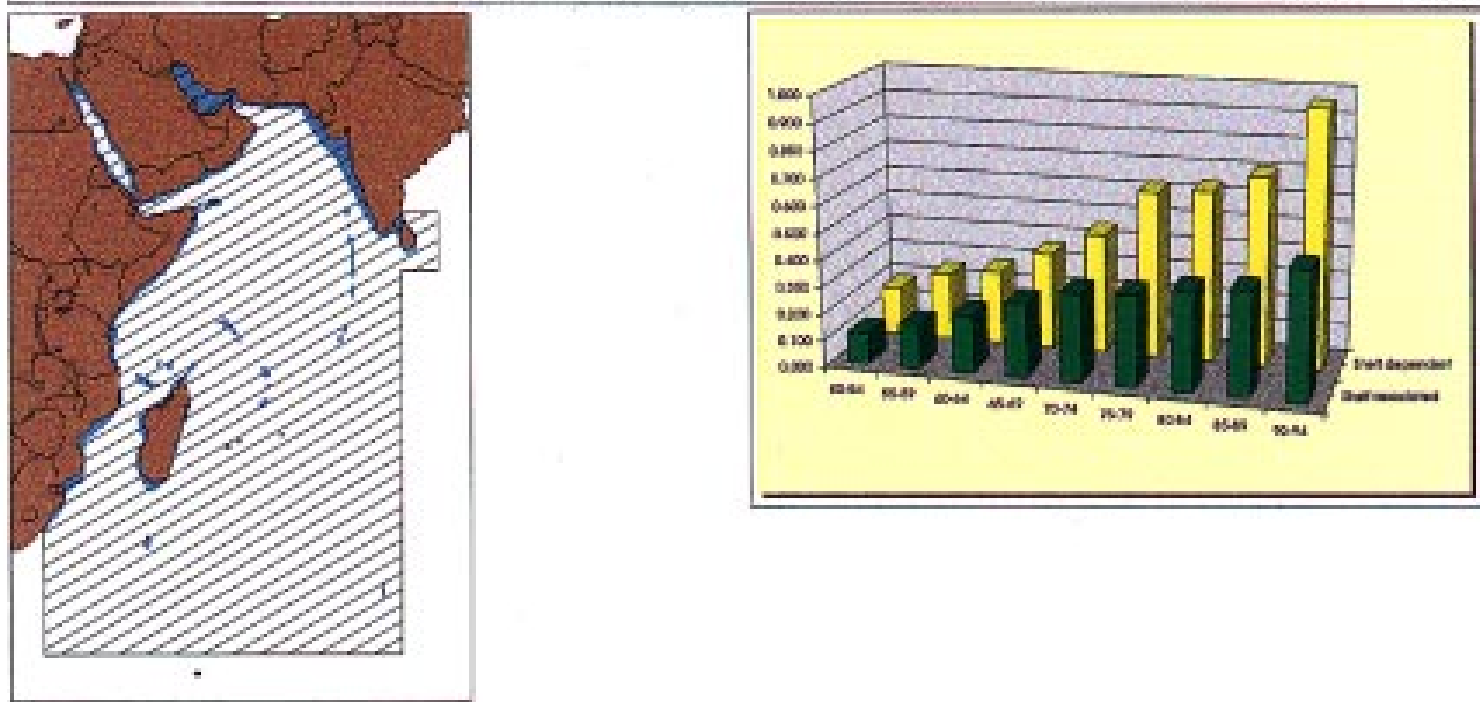

Fig. 4. (Continued). Summarized five-year averages by category and graphed trajectories of mean landings by five-year periods, for Shelf-dependent, Shelf-associated, Oceanic, Deep-water and Total landings from the 15 FAO Statistical Areas considered in this study, for which trends are shown for the five-year averages of the first two. Maps show shelf areas shaded blue. 
FAO Sfatistical Aveas 57 - Indion Ocecr Eastom

Conthental Sheit Surfoce (km²) 2374431

\begin{tabular}{|lcccccccccc|}
\hline Categorles & $50-54$ & $56-59$ & $60-64$ & $65-69$ & $70-74$ & $75-79$ & $80-84$ & $85-89$ & $90-94$ \\
Shelf cssocioled & 0.039 & 0.049 & 0.052 & 0.078 & 0.084 & 0.119 & 0.201 & 0.240 & 0.285 \\
Sheif dependent & 0.046 & 0.055 & 0.061 & 0.089 & 0.124 & 0.232 & 0.295 & 0.340 & 0.458 \\
Oceanic & 0.006 & 0.012 & 0.020 & 0.028 & 0.025 & 0.038 & 0.055 & 0.071 & 0.084 \\
Deep water & 0.010 & 0.007 & 0.004 & 0.007 & 0.010 & 0.014 & 0.015 & 0.015 & 0.013 \\
Total & 0.102 & 0.123 & 0.137 & 0.202 & 0.243 & 0.402 & 0.565 & 0.665 & 0.840 \\
\hline
\end{tabular}
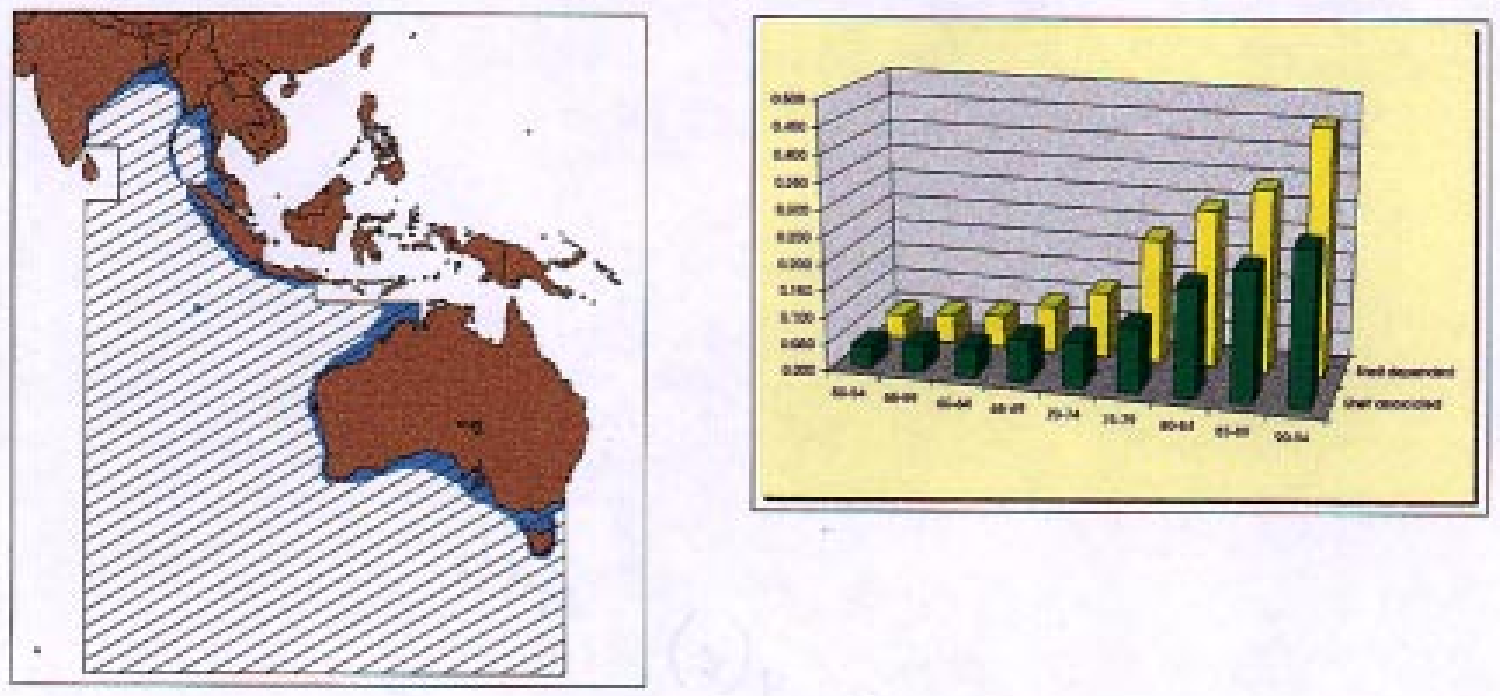

मAO Stchatcal Aveas of - Pochlc Norhwest

Coninental Shet Surlace $\left(\mathrm{km}^{2}\right), 3632571$

\begin{tabular}{|lccccccccc|}
\hline Categorles & \multicolumn{8}{c|}{5 -year periods } \\
Shelf cssocioted & $50-54$ & $55-59$ & $60-64$ & $65-69$ & $70-74$ & $75-79$ & $80-84$ & $85-69$ & $90-94$ \\
Shelf dependont & 0.502 & 0.613 & 0.669 & 0.752 & 0.955 & 1.304 & 1.868 & $\mathbf{2 . 2 1 9}$ & 1.660 \\
Ocearic & 0.619 & 0.892 & 1.143 & 1.449 & 2.103 & 2.707 & 2.636 & $\mathbf{3 . 1 3 1}$ & 2.760 \\
Deep woter & 0.206 & 0.247 & 0.321 & 0.287 & 0.257 & 0.238 & 0.257 & 0.281 & 0.383 \\
Told & 0.073 & 0.120 & 0.134 & 0.151 & 0.191 & 0.162 & 0.189 & 0.168 & 0.218 \\
\hline
\end{tabular}
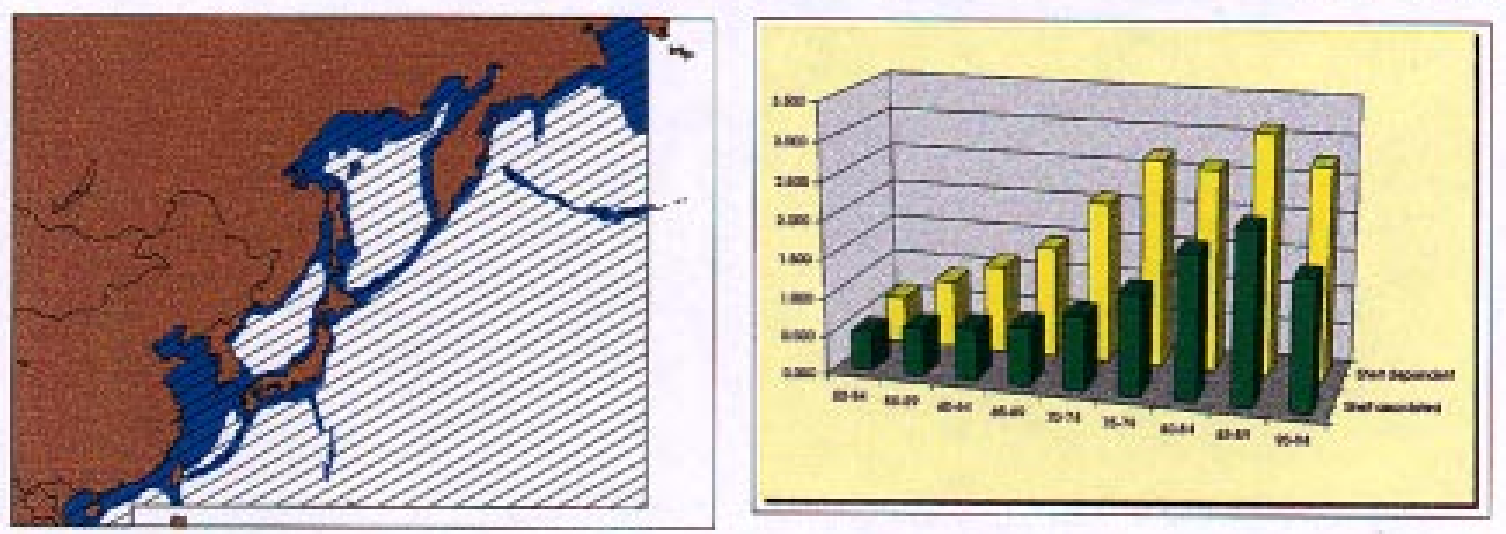

Fig. 4. (Continued). Summarized five-year averages by category and graphed trajectories of mean landings by five-year periods, for Shelf-dependent, Shelf-associated, Oceanic, Deep-water and Total landings from the 15 FAO Statistical Areas considered in this study, for which trends are shown for the five-year averages of the first two. Maps show shelf areas shaded blue. 


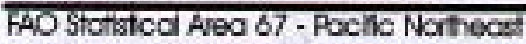
Contnental Shelt Surfoce (km)'s) 1336000

\begin{tabular}{|c|c|c|c|c|c|c|c|c|c|}
\hline \multirow{2}{*}{ Calegoties } & \multicolumn{8}{|c|}{ 5-yeat pericds } & \multirow[b]{2}{*}{$90-94$} \\
\hline & $50-54$ & $55-69$ & $60-64$ & $65-69$ & $70-74$ & $75-79$ & BD- 94 & $85-80$ & \\
\hline Shet associated & 0.137 & 0.145 & 0.207 & 0.094 & 0.085 & 0.076 & 0.059 & 0.061 & $0.08 \mathrm{~B}$ \\
\hline Sheif dependent & 0.168 & 0.221 & 0.605 & 1.174 & 1.696 & 1.461 & 1,460 & 2.072 & 2.022 \\
\hline Oceonic & 0.002 & 0.003 & 0.003 & 0.010 & 0.015 & 0.011 & 0.003 & 0.004 & 0.004 \\
\hline Deep woter & 0.002 & 0.002 & 0.003 & 0.009 & 0.035 & 0.021 & 0.018 & 0.032 & 0.029 \\
\hline Total & 0.309 & 0.371 & 0,817 & 1.286 & 1.831 & 1.569 & 1.540 & 2.169 & 2.123 \\
\hline
\end{tabular}
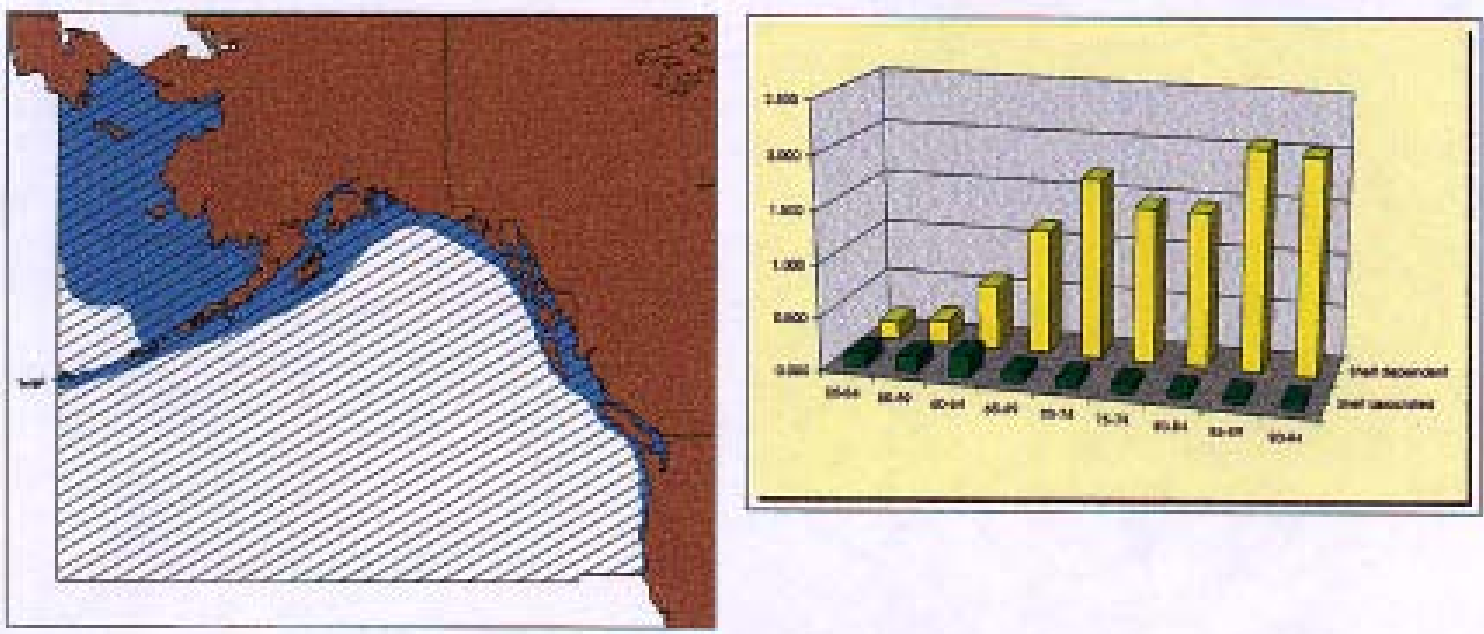

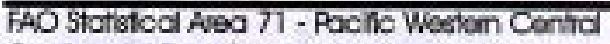
Conthental Shell Surlace $\left(\mathrm{mm}^{2}\right.$ ) 6511255

\begin{tabular}{|lccccccccc|}
\hline & \multicolumn{10}{c|}{5 -year periods } \\
Categories & $50-54$ & $55-59$ & $60-64$ & $66-69$ & $70-74$ & $75-79$ & $80-84$ & $85-89$ & $90-94$ \\
Shelf cssociated & 0.033 & 0.049 & 0.077 & 0.123 & 0.175 & 0.239 & 0.257 & 0.297 & 0.378 \\
Shelf dependent & 0.031 & 0.046 & 0.090 & 0.165 & 0.249 & 0.340 & 0.363 & 0.518 & 0.554 \\
Oceanic & 0.017 & 0.022 & 0.023 & 0.029 & 0.065 & 0.099 & 0.143 & 0.198 & 0.260 \\
Deep water & 0.000 & 0.000 & 0.000 & 0.003 & 0.003 & 0.003 & 0.004 & 0.004 & 0.005 \\
iolai & 0.081 & 0.117 & 0.190 & 0.319 & 0.492 & 0.680 & 0.767 & 1.017 & 1.197 \\
\hline
\end{tabular}
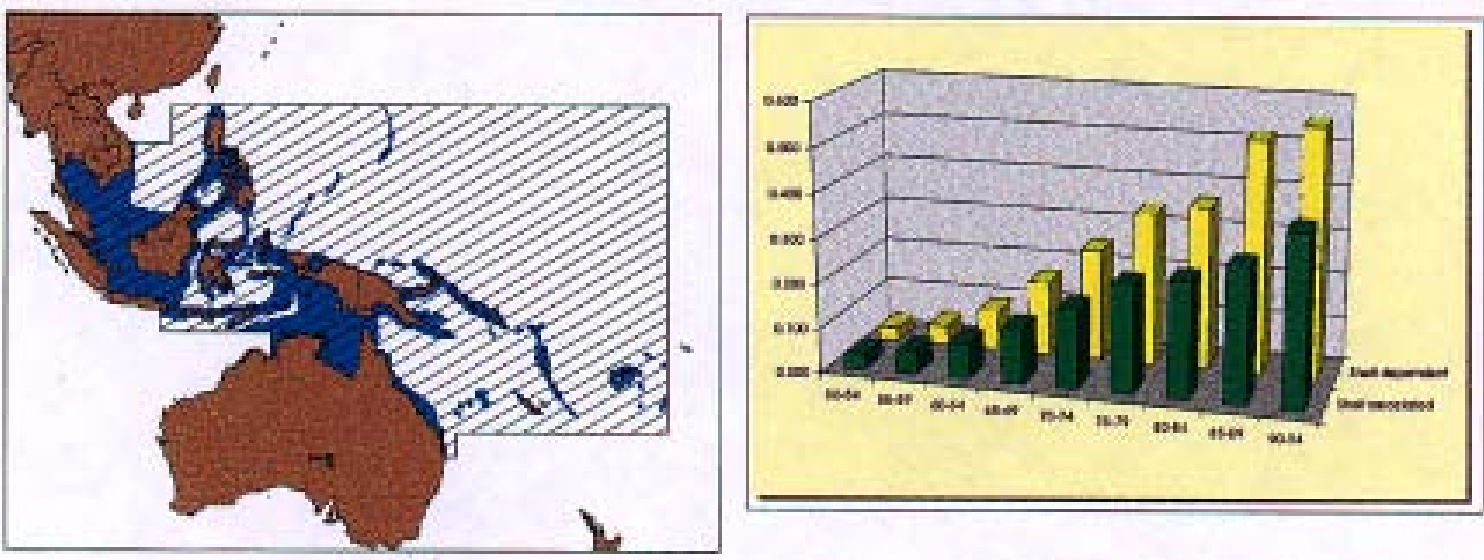

Fig. 4. (Continued). Summarized five-year averages by category and graphed trajectories of mean landings by five-year periods, for Shelf-dependent, Shelf-associated, Oceanic, Deep-water and Total landings from the 15 FAO Statistical Areas considered in this study, for which trends are shown for the five-year averages of the first two. Maps show shelf areas shaded blue. 
FAO Stcistical Aøog 77 - Poclic Eastem Centra Confrental Sheit Surloce $\left(\mathrm{km}^{2}\right)$ : 800465

\begin{tabular}{|lccccccccc|}
\hline Categories & \multicolumn{7}{c|}{5 -yeci periods } \\
& $50-54$ & $55-59$ & $60-64$ & $65-69$ & $70-74$ & $75-79$ & $80-84$ & $85-89$ & $90-94$ \\
Sheit associated & 0.230 & 0.159 & 0.142 & 0.185 & 0.285 & 0.691 & $\mathbf{1 . 0 2 3}$ & 0.996 & 0.612 \\
Sheit dependent & 0.200 & 0.295 & 0.371 & 0.336 & 0.443 & 0.349 & $\mathbf{0 . 4 6 5}$ & 0.443 & 0.397 \\
Ocearic & 0.190 & 0.183 & 0.225 & 0.272 & 0.412 & 0.541 & 0.406 & 0.639 & 0.547 \\
Deep wolec & 0.001 & 0.001 & 0.001 & 0.002 & 0.002 & 0.006 & 0.004 & 0.004 & 0.002 \\
Iotal & 0.621 & 0.638 & 0.739 & 0.795 & 1.143 & 1.587 & 1.966 & 2.082 & 1.558 \\
\hline
\end{tabular}
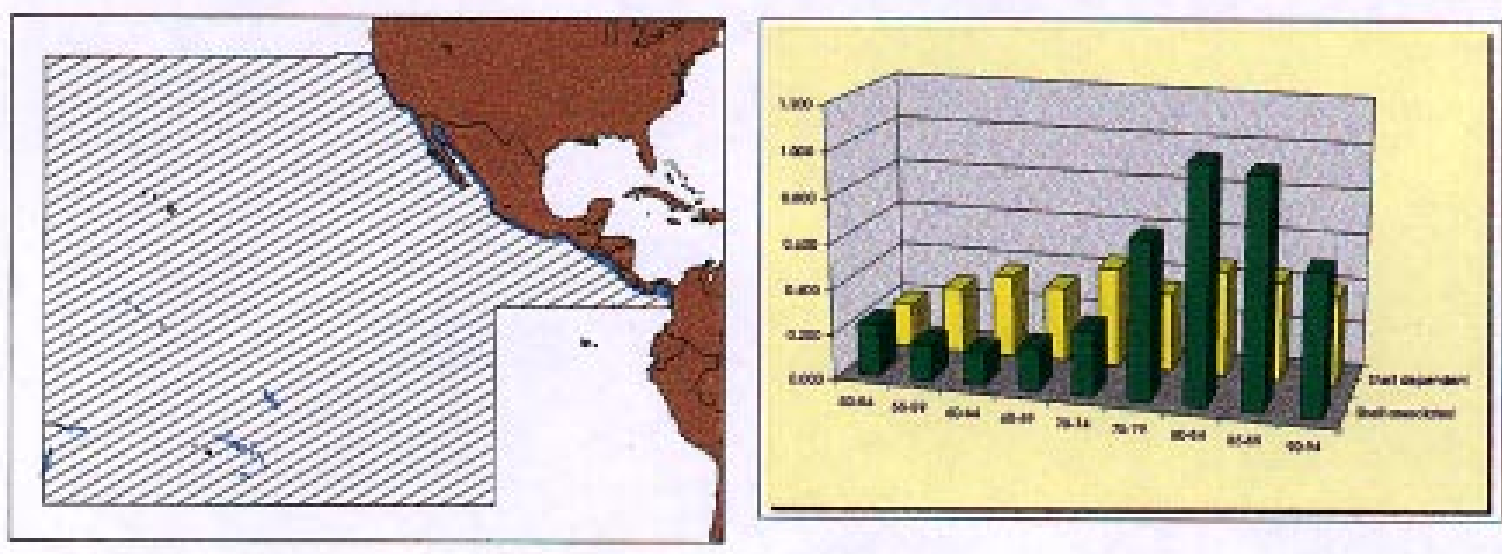

FAC STctistcal Aveo 81 - Pocinc Southwest

Continental Shell Surfoce [am] ; 409520

\begin{tabular}{|c|c|c|c|c|c|c|c|c|c|}
\hline \multirow[b]{2}{*}{ Calegorles } & \multicolumn{8}{|c|}{ 5-year periods } & \multirow[b]{2}{*}{$90-94$} \\
\hline & $50-54$ & $56-59$ & $60-44$ & $65-69$ & $70-74$ & $75-79$ & $80-84$ & $85-89$ & \\
\hline She if asscciated & 0.015 & 0.017 & 0.019 & 0030 & 0.106 & 0.124 & 0.14 & 0.361 & 0.356 \\
\hline Sheif dependent & 0.149 & 0.171 & 0.179 & 0.229 & 0.342 & 0.448 & 0.510 & 0.604 & 0.543 \\
\hline Ocoarie & 0.001 & 0.019 & 0.065 & 0.167 & 0.163 & 0.206 & 0.214 & 0.202 & 0.242 \\
\hline Deep wctor & 0.003 & 0,005 & 0.005 & 0,005 & 0.079 & 0.202 & 0.330 & 0.650 & 0.969 \\
\hline Total & 0.168 & 0.212 & 0268 & 0.431 & $0, B Q 9$ & Q.981 & 1.200 & 1.717 & 2.109 \\
\hline
\end{tabular}
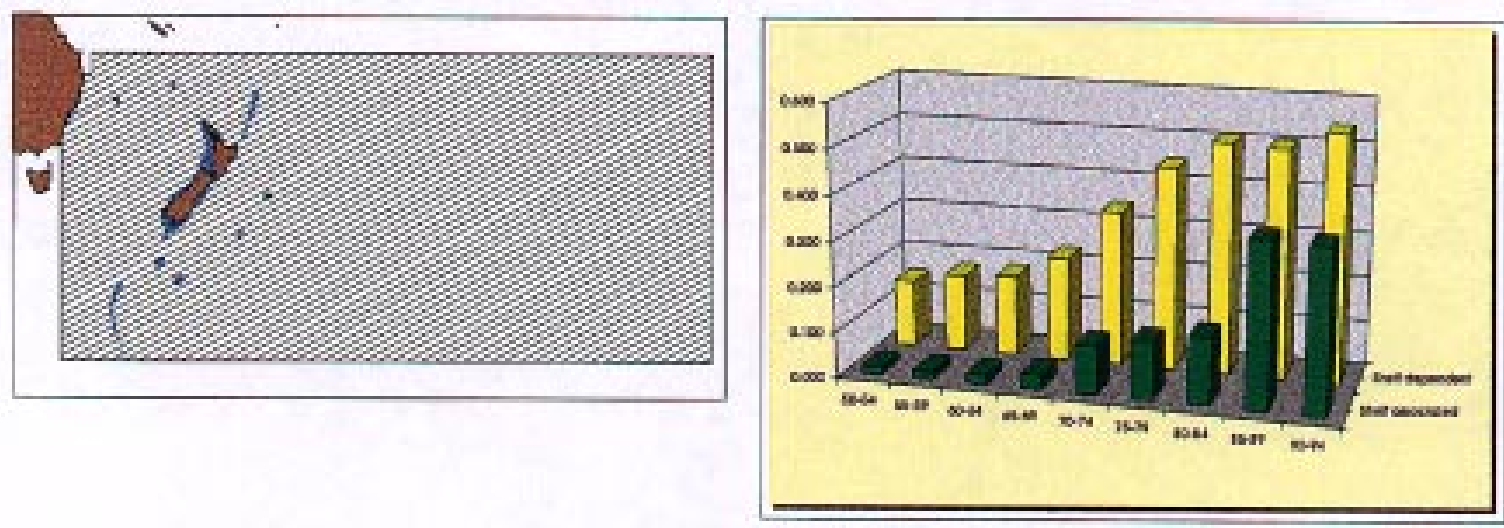

Fig. 4. (Continued). Summarized five-year averages by category and graphed trajectories of mean landings by five-year periods, for Shelf-dependent, Shelf-associated, Oceanic, Deep-water and Total landings from the 15 FAO Statistical Areas considered in this study, for which trends are shown for the five-year averages of the first two. Maps show shelf areas shaded blue. 


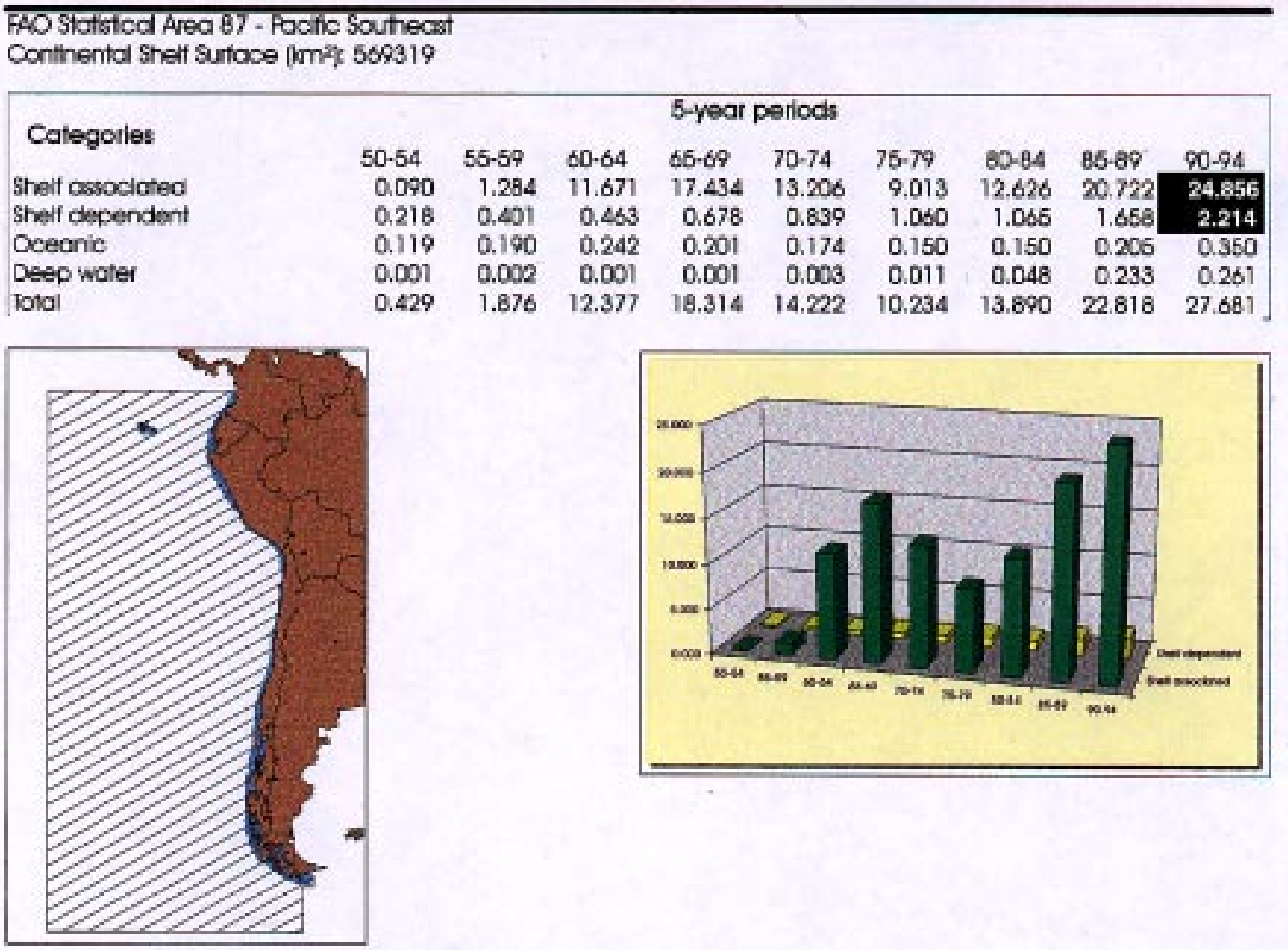

Fig. 4. (Continued). Summarized five-year averages by category and graphed trajectories of mean landings by five-year periods, for Shelf-dependent, Shelf-associated, Oceanic, Deep-water and Total landings from the 15 FAO Statistical Areas considered in this study, for which trends are shown for the five-year averages of the first two. Maps show shelf areas shaded blue.

Table 4. Numbers of peak landings by resource category in each five-year interval, for the 15 FAO Statistical Areas considered.

Interval

Total

(years)

1950-54 1955-59 1960-64 1965-69 1970-74 1975-79 1980-84 1985-891990-94 areas

\section{Resource category}

A. Shelf-dependent

B. Shelf-associated

C. Oceanic

D. Deep-water

$\begin{array}{cccccccc}1 & 1 & 1 & 1 & 2 & 5 & 5 & 15 \\ & 1 & 1 & 1 & 3 & 2 & 6 & 15 \\ & 1 & 2 & & 1 & 2 & 9 & 15 \\ & & 1 & 2 & 1 & 3 & 8 & 14^{1}\end{array}$

1 No significant landings recorded in this Category in FAO Area 31.

shelf-dependent (commercial benthic+demersal fish) production in the same area, but do seem to show a similar trend in timing of peak production globally (Fig. 5). Peak values for pelagic and demersal/benthic fishery production in the two series are loosely correlated for tropical and southern hemisphere resources, but northern hemisphere resources seem to reveal a much higher ratio of commercial benthic+demersal production to small pelagic resources (Fig. 6). The overriding effects of environmental factors on shelfassociated production seem more evident when a comparison is made after taking predominant sources of nutrient production into consideration (Fig. 1). 


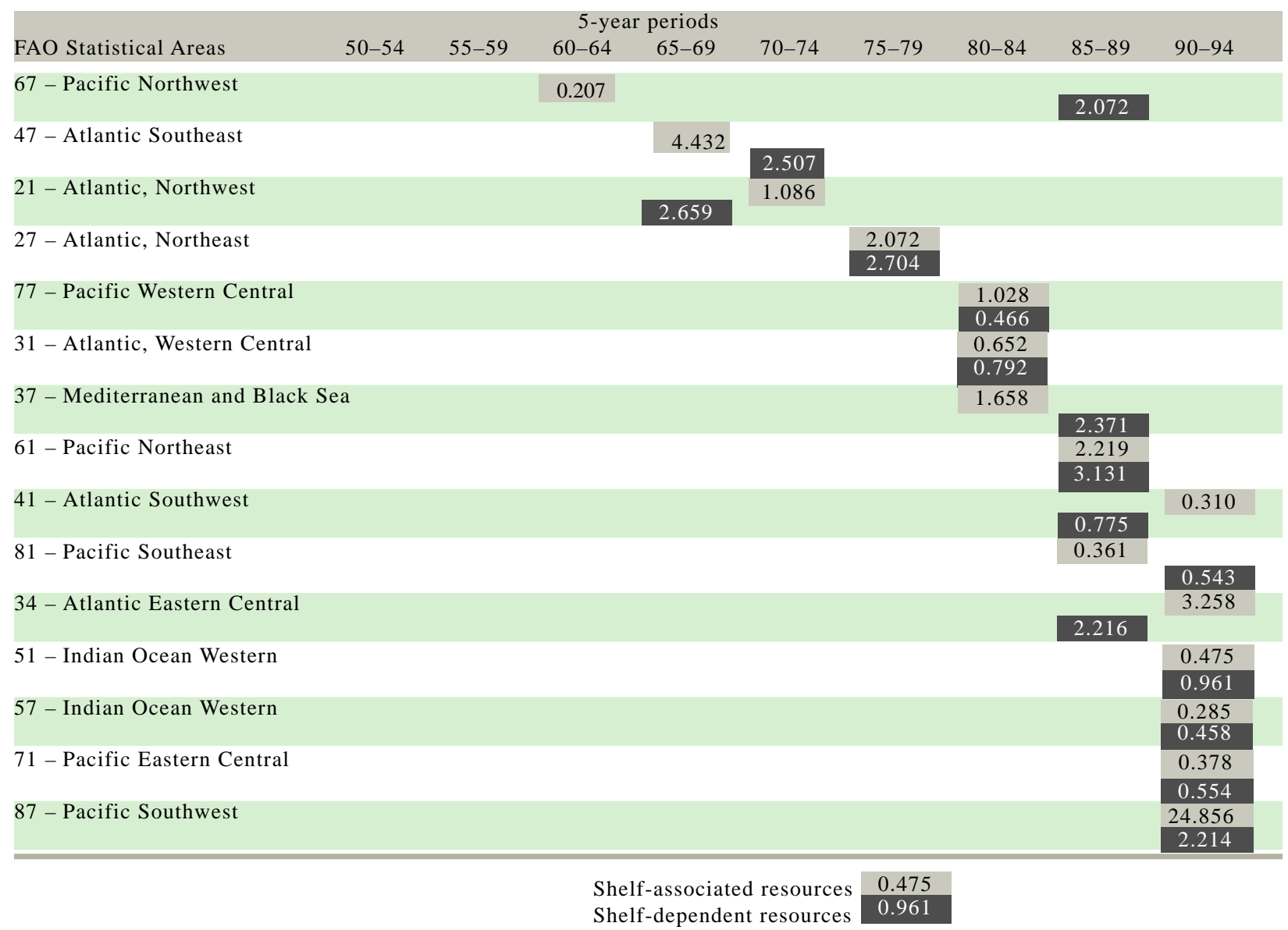

Fig. 5. A tentative ranking of FAO Statistical Areas in terms of the five-year periods for peak shelf-dependent and shelf-associated marine landings per shelf area.

\section{Interpretation of Commercial Fishery Landing Data when Expressed per Shelf Area}

A generalization was searched for which explains the wide variation in these estimates for individual areas. The comparison finally proposed here assumes that the peak values for the five-year averages of total catch per shelf area are comparable measures of the multi-species peak yield for the areas in question in the historical series.

Figure 1 suggests a classification scheme, which appears to explain much of the variation when comparing peak values of mean landings of shelf resources over successive five-year periods. Excluding the four Arctic/Antarctic areas for which catches are relatively low and data fragmentary and not included in this paper, this categorization divides FAO areas into three groups (Fig. 5):

- Northern hemisphere oceanic zones, stretching from the Arctic fringes to temperate/boreal zones ${ }^{3}$.

- Southern hemisphere oceanic zones, stretching up from the Antarctic convergence to southern temperate or boreal latitudes.

3 The north of FAO Area 21 is the only Statistical Area considered where a substantial proportion of the shelf is ice-covered for a major portion of the year, and NAFO Subareas 0 and 1 have shown generally low fisheries productivity. A separate estimate of peak shelf-dependent productivity calculated independently for the southern Subareas of NAFO (2-6 included) in 1965-69 for these southern areas of 3.5 tons per $\mathrm{km}^{2}$, is the highest peak productivity recorded for any FAO Statistical Area. 


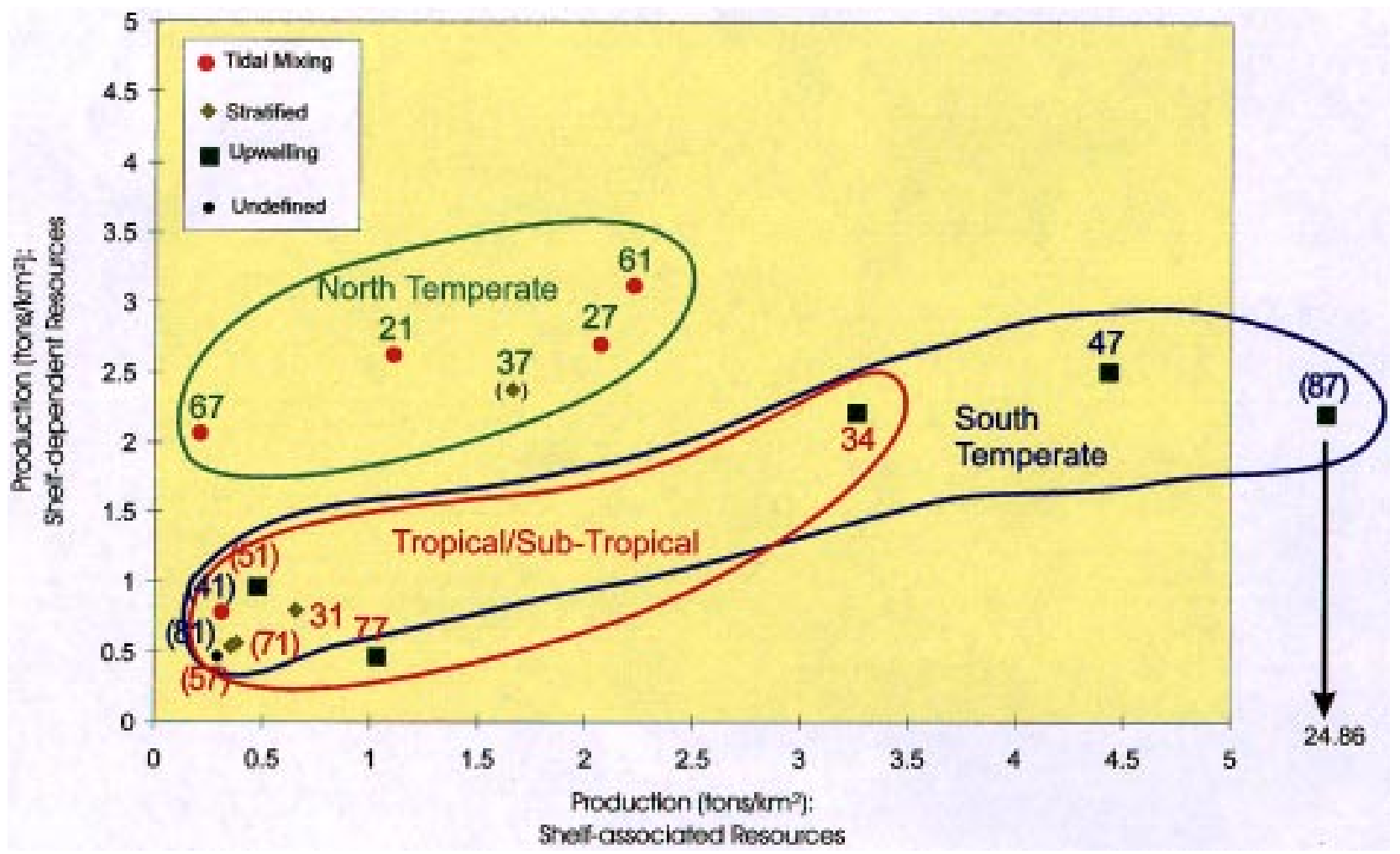

Fig. 6. Shelf-dependent fishing production as a function of shelf-associated fishery production by FAO Statistical Area. This in turn, is believed to be a measure of planktonic productivity. Three geographical categories of FAO Statistical Areas are recognized. (Number in brackets indicates maximum production for area $\mathrm{x}$ is during the last available time interval, 1990-94, and hence may not yet represent a maximum - see text).

- Statistical areas dominated by tropical and/or sub-tropical shelves.

- A semi-enclosed statistical area, the Mediterranean complex of seas (including the Black Sea), is seen as a special category latitudinally and also from its enclosed character. Despite a high fishing intensity since the Second World War, the Mediterranean has shown an increasing landing trajectory. This is in contrast with other "Atlantic" Statistical Areas, but like the Baltic Sea which is part of FAO Area 27, and has shown increases in biomass or standing stock since the early years of this century (Thurow, 1997). This apparent trend for semi-enclosed seas has been tentatively explained for the Mediterranean (Caddy et al., 1995) as a function of progressive nutrient inputs to a marine ecosystem that Gulland (1971) considered very unproductive and nutrient-limited in the 1960s. Effectively, the Mediterranean system can now be considered comparable in productivity with the North Atlantic when expressed in terms of shelf area. Similar explanations have been proposed for rising landings in other semi-enclosed seas (Caddy, 1993).

The above classification allows shelf-dependent production figures to be grouped into three classes, with the following figures for mean production per shelf area with one standard deviation (in brackets):

- Northern hemisphere, Arctic-boreal oceans, including the Mediterranean: 2.588 (s.d: 0.395) tons per $\mathrm{km}^{2}$

- Southern hemisphere, Antarctic-boreal oceans: 1.511 (s.d: 0.995) tons per $\mathrm{km}^{2}$

- Tropical/subtropical oceans: 0.908 (s.d: 0.672) tons per $\mathrm{km}^{2}$ 
It seems from the envelopes drawn around tropical and south-temperate areas in Fig. 6 that there is a similarity in shelf-dependent fishery productivity of these two categories and a marked difference between them and north-temperate regions. Further, it does not seem that the level of peak production of shelf-dependent resources as shown in FAO Areas 31, 74 and 34 of $<1 \mathrm{ton} / \mathrm{km}^{2}$ is going to be greatly exceeded, with the notable exception of upwelling areas.

A linkage between shelf-dependent and shelf-associated resources also appears to be suggested by Fig. 6, but the ratio of the two categories is very different for north-temperate and south-temperate/tropical/ subtropical areas, with a much higher proportion of productivity going into pelagic fish production in the latter categories, especially in upwelling areas. It is difficult to explain this as a result of under-exploitation; given generally higher market values for "shelf-dependent resources" there is likely to be more scope, if any, for increased pelagic landings.

\section{Shelf-associated Fishery Production}

Areas where fishery production is heavily influenced by upwelling of bottom water rich in nutrients tend to be dominated by so-called "small pelagic" fish such as surface feeding sardines, herrings, anchovetas, etc., which, in theory, are usually considered independent on the presence of a shelf for their life history. In practice, however, much of the biomass of small pelagic fish tends to be associated with shelf waters in many statistical areas, especially outside areas where upwellings predominate. Also included in "shelf-associated resources" was a (usually smaller) proportion of medium-sized pelagics such as jacks, horse mackerels, kingfish and neritic tunas (Table 2).

In contrast, yellowfin, skipjack and billfishes, to a significant extent are believed to be independent of shelf waters even though they may be caught there, so that expressing their production as a function of shelf area might be misleading. Thus, although oceanic resources are also expressed per shelf area, this is mainly for comparison with the more neritic resources and with earlier studies, which did not break-down landings in the way done here. As noted earlier, these calculations group maxima reached earlier in the time series with those which peaked in the last five-year period and hence may not yet be maxima.

We may regard small and medium-sized pelagic catches as a second rough indicator of overall fishery production in the area, and perhaps also as a rough indicator of planktonic production. A high level of shelf-associated fishery production per shelf area, not surprisingly, seems largely a function of the presence or otherwise of an upwelling system, a situation that in some areas has led to significant environmentally-driven catch variation, although it is probably true that recent landings of small pelagics in some areas (e.g. the Northeast Pacific) are now constrained in part by market forces. Prior to extension of jurisdiction the potential pelagic production of major producing areas was "tested" by distant water fleets; hence the earlier "maxima" probably do reflect the approximate production potential of each area.

The authors' tentative conclusion is that overall productivity levels for shelf-dependent resources may be close to, or have passed, an upper limit and that, although production may rise further in future in some areas, this will probably be countered by declines in others. With respect to shelf-associated species, wide fluctuations regionally may reflect more environmental change than fishing, but the potential for major long-term increases is probably confined to FAO Area 51 and, to a lesser extent, FAO Area 41, although these increases may occur more in the Deep-water (myctophid) or Oceanic (tuna) categories.

\section{Are the Western Indian Ocean and South Pacific Fully Exploited?}

As noted above and identified by Grainger and Garcia (1996), the area where there seems the most uncertainty about future levels of landings is FAO Area 51, the Western Indian Ocean. Here a major upwelling system operates with high planktonic production but, unlike most other upwelling areas, without correspondingly high level of small pelagic fish production. This area, with its high energy, high production upwelling regime, is characterized by movements of low-oxygen water onto the generally narrow shelf in the monsoon upwelling seasons and has obvious disadvantages for the maintenance of large stocks of demersal fish. Small pelagic fish are remarkably low in abundance relative to tunas, and 
this may result from the absence of an "optimal environmental window" for returning small pelagics larvae to the adult feeding grounds (Bakun et al., in press). Fisheries in the Western Indian Ocean are dominated by tuna resources, which probably rely on the large, but widely dispersed, stocks of mesopelagic fish. These show vertical migrations offshore and seem to be one of the main "reservoirs" of animal protein not yet exploited in the world's oceans. It remains to be seen, however, whether the large scale exploitation of mesopelagics is technically or economically feasible. If it is, their potential yield may make up a major portion of the total yield from the Indo-Pacific Area in our Deep-water category, given stock sizes in northern FAO Area 51 which are at least 20+ million tons (FAO, 1997). Mesopelagics could then possibly make a major contribution to world supplies of fish meal or, alternatively, it is possible that growing levels of tuna production in this area will need to be supported by large stocks of mesopelagics as a food base. It seems unlikely, however, that there is a potential for major increases in shelf-dependent production from conventional shelf fisheries.

Figure 6 also seems to suggest that there is some further potential for increased landings in the South Pacific but, given the narrow shelf areas, the upward potential is surely limited in absence of any particularly well-developed nutrient source, apart from the likely low long-term productivity of fisheries on sea mounts. FAO Area 87, except for its uniquely high pelagic production whose peak productivity has been "tested" at least twice during El Niño episodes in the past, does not seem to have major upward potential for shelf-dependent resources, which may be limited by low oxygen waters in some shelf areas. Further offshore there has recently been shown to be significant (largely realized?) potential for the oceanic squid, Dosidicus gigas and the Chilean jack mackerel (FAO, 1997).

\section{Demersal Fish and Commercial Benthic Invertebrates}

This category with the consistently highest production, and surprising similarity of production figures for shelf-dependent species in peak years, occurs in the northern hemisphere at relatively low corresponding levels of shelf-associated production (Fig. 6), as compared with southern and tropical regions. The dominant nutrient source for these areas appears to be vertical mixing of shelf waters (Fig. 1). While three south-temperate and tropical/subtropical areas such as the Southeast Atlantic, Southeast Pacific and Eastern Central Atlantic have levels of shelf-dependent production that closely approach northern hemisphere areas, these are all eastern boundary current areas characterized by strong upwelling and high levels of biological production and have all experienced well developed industrial fisheries for a decade or more.

The remaining tropical/subtropical and south-temperate areas show significantly lower production figures for both shelf-dependent resources in the range of 0.62 tons per $\mathrm{km}^{2}$ to $<1.00$ tons per $\mathrm{km}^{2}$ and also low rates of capture of shelf-associated resources. Only two of these, the Western Indian Ocean and parts of the Eastern Central Pacific, are characterized by high planktonic production. An extremely energetic upwelling regime exists in the Arabian Sea with low oxygen water seasonally rising onto the shelf, but rather stratified water masses predominate to the south (Fig. 1). All of the other five areas considered are clustered closely around $0.3-0.6$ tons per $\mathrm{km}^{2}$ of shelf-associated resources. The only other area that merits special attention is the Mediterranean/Black Sea which, despite a long history of exploitation, appears to have made the transition over the last two decades from the upper end of the tropical/subtropical range of values of 0.9 tons per $\mathrm{km}^{2}$ in 1970-74 to become more consistent with north-temperate levels of production of over 2 tons per $\mathrm{km}^{2}$, for reasons that have been linked to increased nutrient runoff.

\section{Discussion}

\section{Problems in Categorization of Shelf Ecosystems and Resources}

A classification of major shelf areas in terms of their predominant nutrient sources (see Table 1, after Caddy and Bakun, 1994) seems to point to three main sources: (i) runoff of nutrients from contiguous land masses; it being reasonable to conclude that much of the land runoff of nutrients, plankton and riverborne organics enters food chains potentially leading to fishery resources prior to leaving the shelf; (ii) 
through rivers, introduction of nutrient-rich subsurface water by wind-driven upwelling, and (iii) tidal mixing of surface with enriched bottom water on relatively shallow shelves. Upwelling tends to be initiated close to the shelf break and hence affects productivity on the adjacent shelf and slope, as well as offshore. Tidal mixing is another important mechanism for bringing nutrient-rich bottom water into shelf photic zones. The importance of this type of categorization is that it removes the simplistic assumption that the underlying productivity of each shelf area is the same and provides more realistic targets for overall management of the multi-species resources.

There is a tendency for demersal fish to be more prominent than pelagic fish in sub-Arctic, rather than warmer, waters (Jones and Martin, MS 1981). A further problem is posed by assuming a uniform classification of tropical and cold-temperate fish species in relation to their bathymetric distribution and mode of life, given that many species whose temperate relatives would be regarded as demersal also feed extensively off-bottom, making the boundary with the shelf-associated category blurred. Attempting to divide the FAO database by proportion of organisms and their life history stages performing as benthivores, planktivores and piscivores or by trophic level would, we believe, raise even greater difficulties than the present study, even though preliminary information on the food web structure in many areas is available (e.g. Pauly and Christensen, 1995). We suggest that the production per shelf area categories developed here not be viewed as absolute figures, but they can perhaps provide some idea of relative trends in time by the main categories.

\section{Potential Sources of Biases in the Estimates}

Beginning with Gulland (1971), there has been a search for empirical estimates of fish production for different marine ecosystems, and the focus of the present paper is mainly on fishery productivity of continental shelves. Gulland's estimates, like those presented here, are for the entire fishing area, and should not be compared directly with estimates derived from specific habitats or ecosystems. The use of large, ecologically non-homogeneous statistical areas is, of course, simultaneously a weakness (in that the estimates do not reflect specific ecosystems) and an advantage (in that the overall fishery production of the combined assemblages can be compared between different shelf areas). In contrast, Marten and Polovina (1982) assembled estimates for a wide range of specific aquatic ecosystems from ponds, lakes and rivers to the open ocean, and these range from 0.1 to 30 tons per $\mathrm{km}^{2}$ per year, with most estimates for marine coastal waters and estuaries centred around 3-6 tons per $\mathrm{km}^{2}$ per year.

Most of these latter estimates are for specific, usually high productivity areas and, as they note, overall productivity is spatially distributed in a highly contagious fashion, being centred on 'hot spots' such as estuaries, mangrove swamps, coral reefs and other hard bottom substrates. In the tropics, these estimates drop off rapidly with depth over sand bottoms and usually decline with distance offshore to very low values in most oceanic abyssal areas. With respect to benthic and demersal production, as noted by Thorson (1957), epifaunal communities are well developed in the tropics, but benthic standing stocks and productivity (outside of coastal waters, mangrove swamps and coral reefs) tend to be low, perhaps due to the absence of a spring bloom, which in arcto-boreal latitudes allows biomass to accumulate in the infauna, to be used by demersal fish as food throughout the rest of the year.

A number of problems, which are largely a function of the data and the structure of the database and hence difficult to overcome and impossible to fully quantify with current global data sources, must be noted with this analysis. This makes our analysis largely comparative and indicative, particularly from a trophic/food web perspective. Many of the biases described earlier, although difficult to quantify, tend to operate in contrary directions and, apart from the likely overriding influence of discards, are unlikely to greatly change the overall conclusions reported here. Further attempts to reduce their importance are recommended, and a further emphasis nationally on improving fisheries statistics is suggested.

Table 5 attempts to illustrate the likely direction, if not the extent, of biases for the categories used and some specific examples illustrate these. The Ommastrephidae nei were assigned to "Oceanic resources" but also feed and are caught over the shelf; contrariwise, many hake resources occur deeper than $200 \mathrm{~m}$ 
TABLE 5. Sources and likely directions of probable global biases in the production/shelf area estimators developed here, and their likely relative importance to estimates for the 4 categories shown in the headings.

\begin{tabular}{|c|c|c|c|}
\hline Shelf-dependent Resources & Shelf associated Resources & Deep-water Resources & Oceanic Production \\
\hline $\begin{array}{l}\text { +ve: Catches of "shelf" } \\
\text { invertebrates and } \\
\text { demersals taken below } \\
200 \mathrm{~m} \text { are included here. }\end{array}$ & $\begin{array}{l}\text { +ve: Catches of small } \\
\text { pelagics off the shelf are } \\
\text { included here. }\end{array}$ & $\begin{array}{l}\text {-ve: Catches of "shelf" } \\
\text { invertebrates and demersals } \\
\text { taken below } 200 \mathrm{~m} \text { are not } \\
\text { included here. }\end{array}$ & $\begin{array}{l}\text {-ve: Small-medium sized } \\
\text { pelagics caught off shelf } \\
\text { are not included here. }\end{array}$ \\
\hline $\begin{array}{l}\text {-ve: Oceanic squid catches } \\
\text { on shelf are not included } \\
\text { here. }\end{array}$ & $\begin{array}{l}\text {-ve: Catches of large tuna } \\
\text { in shelf waters are not } \\
\text { included here. } \\
\text { here. }\end{array}$ & $\begin{array}{l}\text { +ve: Some catches of the } \\
\text { deep-water species listed in } \\
\text { Table } 3 \text { are taken in shelf } \\
\text { waters. }\end{array}$ & $\begin{array}{l}\text {-ve: Some "neritic" } \\
\text { tuna catches taken off } \\
\text { the shelf are not included }\end{array}$ \\
\hline $\begin{array}{l}\text {-ve: Inter/sub-tidal and } \\
\text { artisanal catches, and } \\
\text { anadromous catches in } \\
\text { estuaries and on the shelf } \\
\text { are not included here. }\end{array}$ & & & $\begin{array}{l}\text { +ve: Oceanic squid } \\
\text { catches and large Tunas } \\
\text { taken on the shelf are all } \\
\text { included here. }\end{array}$ \\
\hline \multicolumn{4}{|l|}{$\begin{array}{l}\text { Fishery production/shelf } \\
\text { area in the tropics is likely } \\
\text { to be under-estimated close } \\
\text { inshore, and over-estimated } \\
\text { towards the shelf edge and } \\
200 \mathrm{~m} \text { depth. }\end{array}$} \\
\hline -ve (discards) & -ve (discards) & -ve (discards) & -ve (discards) \\
\hline
\end{tabular}

(especially in FAO Area 47) but are assigned here to "Shelf-dependent resources". Similarly, small pelagics are considered "Shelf-associated resources" but also in part feed and are caught in oceanic waters, as for example does a significant proportion of Chilean jack mackerel stocks. Small tuna species, which are assigned to the "Shelf-associated category", to an unknown extent also feed in oceanic waters. Perhaps the two biases that are most important and point predominantly in the direction of a general under-estimate of potential fishery productivity are those due to under-reporting and discarding, and these are the most difficult to estimate or allow for regionally, given current data sources. They must be left to future, more detailed investigation.

\section{Improving Shelf Production Estimates}

We have mentioned earlier the sources of biases in the current estimates, of which non-reporting of discards and under-reporting of catches are undoubtedly more important than those caused by misclassification of landings or errors in measuring shelf areas. The bias due to discards is probably the easiest to estimate, and Alverson et al. (1994) provide a tentative global range of estimates of some 17.9 to 39.5 million tons annually (about $26 \%$ by weight of marine landings for a median value of 27 million tons of discards). In combination, these two most important biases might add globally more than $30 \%$ to the production figures, if for discards one ignores their ecological importance, and the potential recycling in marine food webs leading to harvestable products. Unfortunately, allocating this very provisional total by region presents major problems not solved here.

Other, probably less serious errors are those due to misreporting or misidentification of catches, but these contribute to the uncertainty in the species breakdowns using this database. The approach taken here is that the FAO data set can best be used as an indicator of trends and a generator of research hypotheses to be tested by more exact analyses in individual, smaller and homogenous fishing areas, where it is suggested that production per area estimates be further developed. 
Unlike earlier reports, evidence is presented here that fishery production/shelf area can now be considered to have reached or passed their maxima for most world areas. It seems also that these maxima show a degree of zoogeographic consistency, at least for groundfish and shelf invertebrates. Differently from the small- to medium-sized pelagics whose production is shown to be closely tied to nutrient availability, shelf-dependent resource production seems maximized at intermediate levels of nutrient availability for the FAO Statistical Area concerned.

There seems to be some relationship between shelf-dependent production by latitude and also by hemisphere, with the north-temperate FAO Statistical Areas showing a higher peak fishery productivity for shelf-dependent resources than south-temperate or tropical/sub-tropical statistical areas.

\section{Geographical Distribution of Fisheries Production}

Current estimates of fisheries production outside EEZs (informally estimated at not more than $10 \%$ of world marine production - or 9.1 million tons in 1989 - (FAO, 1995c)) suggest that a large proportion of fisheries production occurs, or is associated with, food chains initiated or completed within shelf waters. This conclusion seems consistent with ocean colour monitoring from satellites and appears also consistent with information from semi-enclosed seas where rapid changes have occurred in the last few decades (Caddy, 1993). The colour plate of global phytoplankton productivity in NSF/NASA (1993) provided for the first time a global synthesis of primary productivity in which coastal waters, and in particular northern-hemisphere Arcto-boreal shelf areas, are indicated as important centres of demersal and commercial invertebrate shelf production than more spectacular areas of upwelling.

Open oceanic areas show very low levels of spectral absorption for wavelengths associated with chlorophyll and are presumably still much lower in biological productivity and fish production than shelf areas. Despite recent discoveries of food webs associated with geothermal vents, they are associated with longer food chains to human consumption (Marten and Polovina, 1982). As noted by Jones and Martin (MS 1981), however, there are no hard and fast rules covering generalizations of this type; rather, categories 1-4 above are indices ranked in terms of their declining efficiency as measures of the fishery productivity of shelf waters, and it is left to the reader to decide whether total shelf productivity is best measured by shelf-dependent and shelf-associated categories separately or whether they should be combined.

\section{Causes of Geographical Variation in Production}

The benthic ecosystem and detrital cycles have been documented as playing a key role for many invertebrate and demersal species in spreading seasonal productivity pulses in the phytoplankton throughout the year, and these are poorly developed in many tropical areas. Together with the reduced bathymetric range of many tropical demersal systems (see e.g. Pauly, 1982) this may be the key to the relatively low demersal productivity in many tropical areas.

A large number of estimates exist in the literature for primary productivity but, although a general relationship exists with fishery yields, this relationship is not very tight (e.g. Marten and Polovina, 1982). Recent estimates of potential productivity based on food web structure (Pauly and Christensen, 1995) suggest that a significant proportion of primary production in shelf areas is now being harvested by man. Marten and Polovina (1982) documented very high estimates of fishery productivity for some coral reef ecosystems of up to 30 tons per $\mathrm{km}^{2}$, and similar high estimates have been made for other localized ecosystems. This contrasts with the low overall values for fisheries productivity of tropical shelf areas we have calculated and reinforces the highly contagious and local nature of shelf-dependent productivity for most tropical ecosystems outside reef or "live-bottom" systems or beyond the area of influence of river runoff and upwelling systems. It also suggests caution to those expecting major returns from exploration for the famous "offshore resources" that have been the subject of major investments on industrial fleets in some tropical countries, based on a misleading analogy with fisheries production from deeper fishing grounds in cold-temperate zones. 
For areas where peak production figures were reached prior to the last five-year interval (1990-94) the historical series may allow one to compare peak levels of production and suggest that other biological, geographical and physical factors that influence landing variations, at current levels of exploitation, may be of greater importance than regional differences in fishing intensity. Variations in peak fishery productivity can then presumably be sought mainly in terms of variations in the underlying biological productivity of the ecosystems in each statistical area. For areas where the last five years is the period of peak production, comparing these five-year averages for demersal and small pelagic resources has an element of uncertainty. However, from other sources of information (e.g. FAO, 1997), it seems that, with certain exceptions such as the western Indian Ocean (Grainger and Garcia, 1996), most shelf resources are close to or fully exploited, hence these "terminal" values for shelf production may not be serious under-estimates.

If this generalization proves to be the case over the next decade, the main conclusion of this paper would seem to be that the limits to fisheries productivity of a shelf area is more a function of type and amount of nutrient sources than simply the level of fishing effort exerted.

One feature of FAO Statistical Areas has had some influence on this study. Antarctic and Arctic Statistical Areas are rather low in terms of fisheries production with generally fragmentary data and are not considered here. One Arctic 'anomaly', however, applies in the case of the North Atlantic, where (unlike Arcto-boreal Statistical Areas in the southern hemisphere and in the North Pacific south of the Bering Straits) two Atlantic Statistical Areas, 21 and 27, extend into the Arctic. Including Arctic waters has probably had a relatively low influence on production per shelf area in FAO Area 27 (the Northeastern Atlantic) due to the warming influence of Gulf Stream drift but it undoubtedly reduces the overall production per shelf area for the Northwest Atlantic, since a significant proportion of shelf areas are in the generally unproductive and ice-covered Northern Labrador Sea and Baffin Bay. Recalculating fisheries productivity for southern NAFO areas by excluding catches and shelf areas of the ice-covered Arctic NAFO Subareas 0 and 1, these southern areas were among the most productive in the world for shelfdependent resources in the 1970s.

The distribution of primary production through all terrestrial and aquatic ecosystems was illustrated in NSF/NASA (1989), based on a composite of a large number of remote sensing images. High levels of chlorophyll pigments were detected by remote sensing in coastal areas and northern latitudes and the generally low fishery production levels implied in oceanic waters and in tropical waters in general, except for upwelling areas and areas under riverine influence. A comparison of northern boreal areas with climatically comparable areas in the southern hemisphere from this imagery shows that these latter areas appear to be relatively lower in shelf-dependent productivity. One obvious explanation here is a "land mass effect", whereby in the northern hemisphere nutrient enrichment by incoming rivers, and possibly improved larval retention on shelves, could play a more important part than on exposed southern hemisphere shelves. We find it difficult to believe that these discrepancies are due to differences in fishing regimes alone, since, even in developing countries areas, intensive fishing by distant water fleets have operated since the 1960s and 1970s. Our estimate of the size of this "land mass" effect on shelf-dependent production of $1.00-1.50$ tons per $\mathrm{km}^{2}$ is very tentative but seems to merit further investigation.

A "land-mass effect" such as postulated here could include the impacts of increased runoff of nutrients and organic carbon, presence of wetlands and estuarine nurseries and the retention of larvae by enclosed bays, all of which could increase fishery production. Indirect confirmation of a positive impact of moderate increases in land runoff on fisheries is provided for inland seas such as the Baltic, Black Sea, Seto inland sea and others (Caddy, 1993) and for the Mediterranean (Caddy et al., 1995). For several major northern river systems such as the Rhine, Weser and Elbe, which together contribute 292000 and 22570 tons per year of nitrogen and phosphorus respectively to the German Bight and Southeastern North Sea (e.g. Larrson et al., 1985) these inputs can be considerable and have even led to anoxic conditions in open sea areas. Other effects could be equally important, primarily the "containment effect" due to the retention of nutrients and larvae in semi-enclosed seas. Marine habitats receiving nutrients from adjacent humid land masses (such as the Chilean fjords) exist, of course, in the southern hemisphere but to a much lower scale, and continental shelves are more exposed to flushing by oceanic waters. 
The data set, despite its deficiencies, does seem to reveal distinct levels of production for regions with different dominant sources of nutrients, and the ratio of shelf dependent to shelf associated species seems to be a useful indicator. The role of anthropogenic nutrification of shelf waters was touched on earlier and, building on the generalizations in Caddy (1993) for inland seas, Fig. 7 proposes a hypothesis explaining the similar impact of nutrient availability on shelf-dependent and shelf-associated resources in natural and anthropogenically modified coastal ecosystems. Such reduced shelf-dependent productivity in upwelling areas was apparently contradicted by the high demersal production in the Southeast Atlantic until 1994, when a long and intensive upwelling episode led to temporary collapse of a number of demersal stocks, apparently mainly due to low oxygen conditions on the shelf. In both anthropogenic and natural nutrient enrichment there seems a reduction in shelf-dependent production at high levels of nutrients despite high shelf pelagic production. These phenomena seem to be linked to low oxygen conditions on shelf areas adjacent to upwellings or sea areas receiving excessive nutrient runoffs.

\section{What is the Potential Yield of the World Oceans?}

As noted, Marten and Polovina (1982) found no single physical or environmental indicator that explained the global variation in fish yields geographically so that, although a knowledge of food webs is important (Pauly and Christensen, 1995), a reliance on empirical measures of production seems inevitable for the moment in making global generalizations. Up until this decade, however, it has been impossible to decide whether productivity figures from different regions corresponded to levels of fishing intensity that could be assumed to correspond to multi-species maxima. Estimates of these peak production levels are

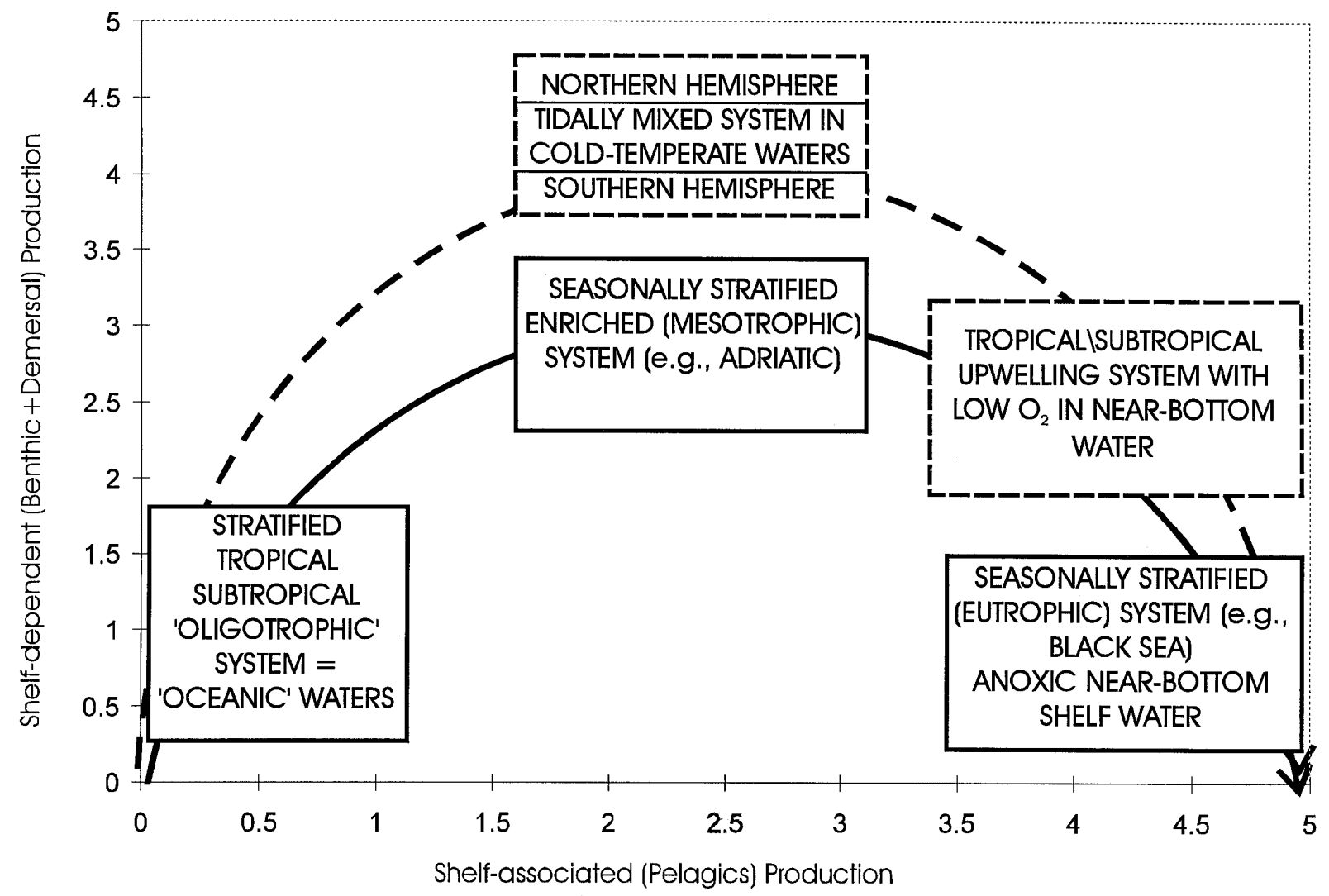

Fig. 7. A proposed transition from low production of shelf-dependent species in oligotrophic stratified waters through moderate (mesotrophic) production on north temperate shelves to lower (eutrophic) production in areas subject to intense upwellings and episodes of low-oxygen in bottom waters. It is suggested this parallels the transition observed as a result of anthropogenically-caused nutrient runoff in semi-enclosed seas (Caddy, 1993). 
now available for many world areas, if we assume that the mean landings averaged over a period of peak production are a measure of the multi-species maximum yield from the ecosystem under the particular exploitation strategy followed. In other areas, this peak period of landings may not yet have been reached, but we may deduce from other information that it is not far distant.

Assuming that ecosystem change is in some sense reversible, a reduction of fishing effort to allow stocks to rebuild to the landing figures that applied in the peak five-year historical series may be an estimate of the potential increase due to improved management. Estimates of this potential improvement by statistical area, and global total, are given in Table 6 for shelf-dependent demersal and benthic production. These estimates may not be realistic if (a) ecosystem change is irreversible and/or (b) the former peak level corresponded in part to "fishing down" of virgin biomass. They nonetheless provide a rough estimate of the potential effects of good management on landings of demersal and benthic resources of the order of 7 million tons globally. (The assumption here, of course, is that it is possible to restore earlier peak periods of landings by improved management, even though reference points for exploitation should be aimed at lower levels of exploitation than under previously largely uncontrolled fishing). This estimate does not include significant gains in landings realizable from reducing the high level of discarding occurring in both high-latitude and tropical fisheries.

Although for North Atlantic waters Jones (1982) showed a progressive decrease from the Arctic southwards in percent demersal fish in the commercial landings, this appears to explain only part of the latitudinal variation observed globally. Variation in production between FAO Statistical Areas seems to demonstrate other regularities based on access to, and type of nutrient sources. The "adjacent land-mass effect" postulated earlier may also play major roles in determining production levels on the shelf and the ratio of production of shelf pelagics and demersal/benthic resources. An indirect estimate by simple subtraction of the order of magnitude of the "land effect" in demersal/benthic fisheries production between northernboreal and southern- and tropical-boreal coastal shelves was mentioned above. By examination of Fig. 6 we may guess this is of the order of some 1.25-1.5 tons per $\mathrm{km}^{2}$ annually for comparable levels of shelf pelagic production. An alternative explanation was offered by Thorson (1957), Alton (1974) and others, i.e. that benthic biomass is higher at higher latitudes and that a seasonal bloom supports greater diversion of planktonic production into benthic-detrital pathways to demersal fish. This does not explain, however, why climatically similar north- and south-boreal shelves show roughly the same marked difference as those also observed between northern and tropical shelves.

TABLE 6. Difference between peak five-year mean value for shelf-dependent production and that for the last fiveyear period in the statistics.

\begin{tabular}{ccccc}
\hline \hline $\begin{array}{c}\text { FAO Statistical } \\
\text { Area }\end{array}$ & $\begin{array}{c}\text { 1990-94 level } \\
\left.\text { (tons per km }{ }^{2}\right)\end{array}$ & $\begin{array}{c}\text { Peak level } \\
\left.\text { (tons per km }{ }^{2}\right)\end{array}$ & $\begin{array}{c}\text { Difference } \\
\left.\text { (tons per km }{ }^{2}\right)\end{array}$ & $\begin{array}{c}\text { Equivalent drop in tonnage } \\
\text { landed from peak (millons of tons) }\end{array}$ \\
\hline 21 & 2.428 & 3.500 & 1.072 & 1.360 \\
27 & 2.378 & 2.704 & 0.326 & 0.930 \\
47 & 0.830 & 2.510 & 1.68 & 0.505 \\
67 & 2.022 & 2.072 & 0.05 & 0.057 \\
77 & 0.397 & 0.466 & 0.069 & 0.023 \\
37 & 1.416 & 2.371 & 0.955 & 0.653 \\
31 & 0.710 & 2.371 & 1.661 & 2.338 \\
41 & 0.698 & 0.775 & 0.077 & 0.138 \\
61 & 2.760 & 3.131 & 0.371 & 0.038 \\
34 & 2.010 & 2.220 & 0.21 & 0 \\
81 & 0.543 & 0.543 & 0 & 0 \\
57 & 0.458 & 0.458 & 0 & 0 \\
81 & 0.96 & 0.96 & 0 & 0 \\
71 & 2.214 & 2.214 & 0 & 0 \\
\hline
\end{tabular}


The conceptual model for the dynamics of an evolving fishery followed in this paper reflects quite well events at the multispecies level, and although it is not in direct conflict with simple single-species numerical models (e.g. production models), there seem few grounds for optimism at the macro level that a reversal of historical increases of fishing intensity has accounted for declining landings. What we seem to be observing is what has been called a "one-way trip" (Hilborn and Walters, 1992), namely the movement from moderate to fully or over-exploited conditions in those fisheries which have been subject to industrial fishing under the effectively open-access conditions that have largely prevailed up to this time. There may be reasons, of course, for supposing that still greater yields could be taken in properly managed fisheries, if stocks were first allowed to recover. Certainly, the strategies followed in the expansion phase of world fisheries did not take into account ecosystem management concepts, the effects of nutrient availability, and the potential for habitat improvement shown in freshwater ecosystems. In this connection, Marten and Polovina (1982) and Caddy and Sharp (1986) note that if stocks are fished in an "intricate" fashion, involving targeting the species mix in an optimal way with a range of selective gears and limited wastage, this would certainly somewhat increase production. Perhaps overall, the allocation of user rights may also lead to controlled exploitation patterns yielding a greater ecosystem yield than presently is the case.

\section{References}

ALTON, M. S. 1974. Bering Sea benthos as a food resource for demersal fish populations. In: Oceanography of the Bering Sea. D. W. Hood and E. J. Kelly (eds.). NOAA, NMFS North West Fish Centre. Seattle, WA, USA, p. 257-77.

ALVERSON, D. L., M. H. FREEBERG, S. A. MURAWSKY, and J. G. POPE. 1994. A global assessment of fisheries by-catch and discards. FAO Fish. Tech. Pap., 339, 233 p. + disk.

BAKUN, A., C. ROY, and S. LLUCH-COTA. (in press). Coastal upwelling and other ecosystem processes controlling the marine resource productivity of the Western Indian Ocean. In: Status and future of the large marine ecosystems of the Indian Ocean. E. Okemwa, M. Ntiba and K. Sherman (eds.). Blackwell Scientific Publications, (in press).

CADDY, J. F. 1984. An alternative to equilibrium theory for management of fisheries. In: Abstracts of papers presented at the Expert Consultation on the Regulation of Fishing Effort (Fishing Mortality). Rome, 17-26 January 1983. A preparatory meeting for the FAO World Conference on Fisheries Management and Development. FAO Fish. Rep., 289(Suppl. 2), 214 p.

CADDY, J. F. 1993. Toward a comparative evaluation of human impacts on fishery ecosystems of enclosed and semienclosed seas. Reviews in Fisheries Science, 1(1): 57-95.

CADDY, J. F., and G. D. SHARP. 1986. An ecological framework for marine fisheries investigations. FAO Fish. Tech. Pap., 238: 152 p.

CADDY, J. F., and A. BAKUN. 1994. A tentative classification of coastal marine ecosystems based on dominant processes of nutrient supply. Ocean and Coastal Management, 23: 201-11.

CADDY, J. F., R. REFK, and T. DO CHI. 1995. Productivity estimates for the Mediterranean: Evidence of accelerating ecological change. Ocean and Coastal Management, 26(1): 1-18.

FAO. MS 1993. World fisheries ten years after the adoption of the 1982 United Nations Convention on the Law of the Sea. COFI Doc., No. 4.

1994. FAO Yearbook of Fisheries Statistics: Catches and landings, Vol. 78, 700 p.

1995a. 1950-1993. World fishery production. Supplement to the FAO Yearbook of Fishery Statistics 1993, Vol. 76, Catches and landings.

1995b. Review of the state of world fishery resources: marine fisheries. FAO Fish. Circ., 884: 105 p.

1995c. The State of World Fisheries and Aquaculture. FAO, Rome, 1995, 57 p.

1995d. Code of conduct for responsible fisheries. FAO, Rome 1995, 46 p.

1997. Review of the state of world fishery resources: marine fisheries. FAO Fish. Circ., 920: 173 p.

GRAINGER, R. J. R., and S. M. GARCIA. 1996. Chronicles of marine fishery landings (1950-1994): Trend analysis and fishery potential. FAO Fish. Tech. Pap., 359: 51 p.

GULLAND, J.A. (ed.). 1971. The fish resources of the oceans. Fishing News Books, West Byfleet, UK.

HILBORN, R., and C. J. WALTERS. 1992. Quantitative fisheries stock assessment: Choice, dynamics and uncertainty. Chapman and Hall, New York, N.Y., 569 p.

LARRSON, U., R. ELMGREN, and F. WULFF. 1985. Eutrophication and the Baltic Sea: causes and consequences. Ambio, 14: 9-14.

JONES, R. 1982. Ecosystems, food chains and fish yields. In: D. Pauly, and G. I. Murphy (eds.), Theory and management of tropical fisheries. ICLARM Conf. Proc., 9: 195-239. 
JONES, R., and J. H. A. MARTIN. MS 1981. The relationship between demersal fish landings and bottom temperature. ICES C.M. Doc., No. G:44.

MARTEN, G. G., and J. J. POLOVINA. 1982. A comparative study of fish yields from various tropical ecosystems. In: Theory and management of tropical fisheries. D. Pauly and G. I. Murphy (eds.). ICLARM Conf. Proc., 9: 255-85.

NSF/NASA. 1989. Ocean colour from space. A folder of remote sensing imagery and text prepared by the NSF/ NASA-sponsored US Global Ocean Flux Study Office, Woods Hole Oceanographic Institute, Woods Hole, MA USA.

PAULY, D. 1982. The fishes and their ecology. In: Small-scale fisheries of San Miguel Bay, Philippines: biology and stock assessment. D. Pauly, and A. N. Mines (eds.). ICLARM Tech. Rep., 7: 15-24.

PAULY, D., and V. CHRISTENSEN. 1995. Primary production required to sustain global fisheries. Nature, 374: 255-57.

THORSON, G. 1957. Bottom communities (Sublittoral or shallow shelf). Treatise on Marine Ecology and Paleoecology, Vol 1, Geol. Soc. America, Memoire, 67: 461-534.

THUROW, F. 1997. Estimation of the total fish biomass in the Baltic Sea during the 20th Century. ICES J. Mar. Sci., 54: $444-61$.

UN. 1995. Agreement for the implementation of the provisions of the United Nations Convention on the Law of the Sea of 10 December 1982 relating to the conservation and management of straddling fish stocks and highly migratory fish stocks. General Assembly Document A/CONF. 164/37, 8 September 1995. 
